\title{
How Stable Are Corporate Capital Structures?
}

\author{
HARRY DeANGELO and RICHARD ROLL*
}

Journal of Finance forthcoming

March 2011

Revised August 2013

\begin{abstract}
Leverage cross sections more than a few years apart differ markedly, with similarities evaporating as the time between cross sections lengthens. Many firms have high and low leverage at different times, but few keep debt-to-assets ratios consistently above 0.500. Capital-structure stability is the exception, not the rule, occurs primarily at low leverage, and is virtually always temporary, with many firms abandoning low leverage during the post-war boom. Industry-median leverage varies widely over time. Targetleverage models that place little or no weight on maintaining a particular leverage ratio do a good job replicating the substantial instability of the actual leverage cross-section.
\end{abstract}

*Harry DeAngelo is with the University of Southern California. Richard Roll is with UCLA. This research was supported by the Kenneth King Stonier Chair at the USC Marshall School of Business and by the Joel Fried Chair at the UCLA Anderson School of Management. Special thanks are due Cam Harvey, the Editor, for many useful comments that helped improve this paper. For helpful comments, we also thank three referees, an Associate Editor, the Co-Editor (John Graham), as well as Tony Bernardo, Fabio Braggon, Daniel Carvalho, Steve Cauley, Tom Chang, Tom Copeland, Linda DeAngelo, Andrea Eisfeldt, Eugene Fama, Wayne Ferson, Murray Frank, Stuart Gabriel, Mark Grinblatt, Gareth James, Lyndon Moore, Kevin J. Murphy, Oguzhan Ozbas, Chris Parsons, Gordon Phillips, Jay Ritter, Lori Santikian, Eduardo Schwartz, Berk Sensoy, Piet Sercu, Douglas Skinner, René Stulz, Avanidhar Subrahmanyam, Ivo Welch, Mark Westerfield, and Toni Whited. We thank Ed Tinoco for help in accessing data from the pre-CRSP/Compustat era, and Amy Allen, Xiaolin Gong, Richard Graham, Mauri Gustafson, Michael Neagoe, Jonathan Pack, and Matthew Wong for superb work on that data. We also thank Chao Zhuang for outstanding research assistance. 
The view that corporate leverage is stable pervades the empirical capital structure literature, and has fostered a belief that the main puzzle facing researchers is to explain cross-firm variation in leverage. Lemmon, Roberts, and Zender (2008, LRZ) find highly significant firm fixed effects in panel leverage regressions, and conclude that firms with high (low) leverage tend to remain as such for two decades and longer, and that time-varying determinants are unlikely explanations for capital structure heterogeneity. Frank and Goyal (2008) report that aggregate leverage stays in a narrow band over long horizons, cite LRZ for firm-level stability evidence, and conclude: "a satisfactory theory must account for why firms keep leverage stationary." Parsons and Titman (2008) and Graham and Leary (2011) highlight significant firm fixed effects and the need to identify time-invariant determinants of leverage. Rauh and Sufi (2011) cite the high $R^{2}$ s for firm fixed effects, and conclude: "the extant research strongly argues that crosssectional variation in corporate capital structure is where researchers should focus."

Although a consensus has apparently congealed around leverage stability as a "fact," illustrative leverage plots such as Figure 1 seem to capture significant instability. This figure records leverage ratios of GM, IBM, and Kodak from 1926 to 2008. Within-firm variation is large for all three, with market leverage varying more widely than book. IBM has had long periods of leveraging and deleveraging, and large time-series variation also characterizes GM's leverage, although both had relatively stable leverage in the 1960s and 1970s. Kodak had stable (near-zero) leverage for many years, but leverage skyrocketed in the 1980 s, followed by marked deleveraging and re-leveraging.

Figure 1 here

Leverage plots for 21 other Dow Jones Industrial Average (DJIA) firms also show substantial instability (see Appendix A). Some of these firms have had only small variation in leverage for extended periods, but none has permanently kept even approximately stable leverage. Virtually all have had low and high leverage at different times. Dramatic leverage spikes abound, and long and substantial drifts both levering up and deleveraging - are commonplace. These examples suggest there is much yet to be learned about whether, or in what sense, capital structures are aptly described as stable.

This paper provides a comprehensive analysis of capital structure stability over long horizons. 
Our most important finding is that leverage cross-sections more than a few years apart differ markedly, with differences growing each year - and not reverting or stabilizing - until there is almost no similarity in cross-sectional snapshots taken at different times.

Stability of the leverage cross-section means that a firm's current high or low leverage (relative to other firms) reliably predicts a comparable relative position in future cross sections. Significant firm fixed effects in leverage panels do not establish stability of the cross section. They only indicate reliable differences across firms in their time-series average leverage ratios calculated over all years in a panel. Such differences do not rule out large changes in the relative leverage positions of firms in cross sections that prevail at different times. Firm-time interaction effects are highly significant in our panel leverage analyses, indicating that firm-specific time-series variation in leverage is systematically important.

We gauge the extent of instability in the cross section by assessing the explanatory power of the current cross section for future cross sections going forward one year at a time and extending well into the future. We find that the similarity between cross sections is short-lived, declining sharply over five to 10 year horizons, and thereafter continuing to erode to near-zero levels.

Migration over the cross section is pervasive: $69.5 \%$ of firms listed for 20-plus years have book leverage ratios that appear in at least three different sample quartiles, and $30.4 \%$ have leverage in all four quartiles at different times over the average 20-year period. Vestiges of similarity in cross sections remain at horizons of 15 or 20 years, and this fact reflects our finding that leverage stability does occur from time-to-time at individual firms. However, extended periods of stability arise only infrequently. When they do arise, firms generally have low leverage and stability is virtually always temporary.

The evaporating similarity of cross sections raises questions about the empirical relevance of leverage targeting. For example, it suggests that Miller's (1977) neutral-mutation view - no targets, random evolution - might plausibly explain leverage behavior over long horizons. The possibility is not ruled out by prior findings of a positive speed-of-adjustment (SOA) to leverage targets, given Chang and Dasgupta's (2009) finding that such SOAs could simply be an artifact of random financing behavior.

We conduct simulations that gauge the ability of random financing and a variety of leverage- 
targeting models to replicate the instability of the cross section over long horizons. Models with timevarying target ratios that vary by large amounts do the best job according to our statistical measure of overall goodness of fit. Models with flexible target zones and those with SOAs to stationary target ratios near $15 \%$ per year also do well, but not as well as time-varying target models. In terms of economic significance, there are only small differences among these three models based on closer examination of the components of our goodness-of-fit measures. These three forms of leverage targeting all clearly dominate models that posit (i) target zones with relatively inflexible bounds, (ii) SOAs toward stationary targets of $30 \%$ or more per year, or (iii) no targeting and random evolution, as in Miller (1977).

If forced to choose a "best" model for explaining the evolution of the leverage cross-section, time-varying targets would be our choice. However, we believe that the most reasonable view is that our findings narrow the set of credible models, but do not clearly identify a single "best" model. These findings indicate that credible models will include targeting behavior, not indifference among all leverage ratios. They also indicate that empirically plausible forms of targeting allow wide leverage variation, and thus are limited to those that place little or no weight on staying near a particular debt/equity mix. Such variation in leverage can arise from large changes in target ratios (e.g., as in Frank and Shen (2013)) or because firm value changes at most by small amounts when leverage varies widely (e.g., as in Korteweg (2010), van Binsbergen, Graham, and Yang (2010) and Korteweg and Strebulaev (2013)).

We document large instability in industry-median leverage ratios, with industry-specific timeseries variation comparable in importance to (previously identified) cross-industry leverage differences that exist at a point in time. These findings are suggestive of target leverage ratios that change a lot over time, but a closer look at the data indicates there is much that we simply do not know about time-series variation in leverage. For example, the leverage changes around departures from stable leverage regimes are typically far larger than contemporaneous changes in target-ratio estimates based on industry-median leverage and other previously identified determinants. There is a strong association between departures from leverage stability and company expansion, which stands out in bold relief during the post-war boom as firms abandoned conservative leverage en masse as they borrowed to fund expansion. 
Section VI has a compact summary of our findings and a detailed discussion of their implications for credible theories of capital structure. Section I provides basic facts about leverage variation over time. Section II presents panel leverage analyses with firm-time interactions. Sections III and IV document the instability of the cross section, and analyze the ability of alternative models to replicate that instability. Section V provides evidence on industry leverage and time-varying leverage targets.

\section{Basic facts: Time-series variation in leverage}

We analyze 15,096 industrial firms in the CRSP/Compustat file over 1950 to $2008 .{ }^{1}$ To gauge leverage behavior over long horizons, we often focus on the subset of 2,751 firms with 20 or more years on Compustat, and on a "constant composition" sample of 157 firms listed from 1950 to at least 2000. The former group accounts for $92.9 \%$ of total market capitalization and $91.7 \%$ of book assets in the median year over 1950 to 2008 , and the latter accounts for $44.1 \%$ and $41.4 \%$. We also analyze handcollected leverage data back to before the Great Depression for 24 Dow Jones Industrial Average (DJIA) firms in the constant composition sample; the Internet Appendix describes the DJIA sample.

Panel A of Table I reports the time-series range and standard deviation of book leverage, market leverage, and the net-debt ratio. Book leverage is the ratio of total book debt (excluding non-financial liabilities) to total book assets, and is denoted Debt/TA. Market leverage is book debt divided by the sum of book debt plus the market value of common stock. The net-debt ratio is book debt minus cash divided by book assets.

Table I here

Large time-series variation in leverage is the norm. For example, among firms listed 20-plus years, the median range in Debt/TA is 0.391 , while it is 0.536 and 0.599 for market leverage and the netdebt ratio. The median standard deviations imply +/- two-sigma bands close to these wide ranges. Firms listed less than 20 years also show nontrivial time-series variation in leverage, although as expected, the

\footnotetext{
${ }^{1}$ Industrial firms are those with SIC codes outside the ranges 4900 to 4949 (utilities) or 6000 to 6999 (financials). The sample excludes firms incorporated outside the U.S. and those not assigned a CRSP security code of 10 or 11. A firm enters the sample the first year it has non-missing values for total assets and share price, and stays as long as Compustat continues to report non-missing values of total assets and its shares remain listed.
} 
ranges are not as wide as they are for firms listed 20-plus years. While market leverage shows greater variation than book, the difference is perhaps not as great as one might have expected. The reason is that the correlation between book and market leverage is 0.878 for the median sample firm, and similarly high correlations pervade the sample. [See the Internet Appendix for details.]

In what follows, we focus on book leverage in part because these high correlations suggest there is not much incremental information in the market series and because, as intuition suggests and Table I confirms, book variation probably provides a lower bound on the instability in market leverage.

Long periods of leverage stability occur infrequently at industrial firms. Operationally, panel B of Table I defines a stable regime to mean that Debt/TA remains in a band of width 0.050 , as would be the case, e.g., when it stays between 0.324 and 0.374 . We also consider two weaker definitions of a stable regime: Debt/TA consistently remains in bandwidths of 0.100 or 0.200 . The table reports the longest stable regime for firms listed 20-plus years and for the constant composition sample.

The data show that (i) a nontrivial minority of firms has a sub-period of moderate length in which leverage remains reasonably stable, and (ii) virtually no firms have permanently stable regimes. On the first point, $21.3 \%$ of firms listed 20-plus years keep leverage in a bandwidth 0.050 for 10 years or more, i.e., about one in five such firms have at least one decade-long period of leverage stability. The incidence of firms with 10-plus years of such stability increases to $51.6 \%$ in the constant composition sample, where all firms are listed for more than 50 years. Stable regimes over longer periods are much less common. For example, only $7.6 \%$ and $2.5 \%$ of firms in the constant composition sample keep Debt/TA in a bandwidth of 0.050 for 20 and 30 years, and none does so for 40 years.

We find a much higher incidence of stable leverage regimes using a weaker definition of stability in which Debt/TA remains in a 0.200 bandwidth. For example, $51.0 \%$ of the 157 firms in the constant composition sample have a period of at least 30 years in which Debt/TA varies no more than 0.200. On the other hand, only $14.6 \%$ of these firms have leverage stay in a 0.200 bandwidth for 40 years or more. This indicates it is uncommon to see even weakly stable regimes that persist for 40 years.

When stable regimes do occur, they largely arise at low leverage, as shown in panel A of Table II. 
For this analysis, we first identify the longest stable leverage regime for each firm (as in panel B of Table I) and then calculate the firm's median Debt/TA during each such regime. We find that 115 firms keep Debt/TA in a 0.050 bandwidth for at least 20 years, and 994 firms do so for 10 years. A remarkable $100.0 \%$ of the former and $88.8 \%$ of the latter have median Debt/TA of 0.100 or less during their stable regimes. Comparably low leverage also characterizes the $78.8 \%$ (and 62.2\%) of firms that keep Debt/TA in a bandwidth of 0.100 for 20 years (10 years). Strebulaev and Yang (2013) repeat this analysis on their sample, and concur that stable regimes arise mainly at low leverage, while Minton and Wruck (2001) find that low leverage is largely a transitory phenomenon.

Table II here

The distribution of leverage maxima and minima for firms listed 20-plus years is reported in Panel B of Table II. We find that $77.5 \%$ of these 2,751 firms have had Debt/TA ratios below 0.100 at some point (rows 1 and 2), while $92.8 \%$ have had Debt/TA below 0.200 (rows 1 to 3 ) and $42.2 \%$ have had no debt outstanding (row 1). Thus, conservative leverage is observed at some point at a large majority of firms. We also find that $62.1 \%$ of these firms have had Debt/TA above 0.400 at other points in time, but aggressive leverage is less common, with only $15.5 \%$ of firms ever having Debt/TA above 0.700 (row 10). Only $0.2 \%$ of firms always keep Debt/TA above 0.500 (rows 7 to 9).

In sum, the data show that (i) substantial within-firm variation in leverage is the norm for publicly held industrial firms, (ii) extended periods of leverage stability arise on occasion, but permanently stable leverage is rare, (iii) stable leverage regimes arise mainly at low leverage, and (iv) although high leverage is observed reasonably frequently, it is almost always temporary.

\section{Systematic importance of time-varying leverage determinants}

Mackay and Phillips (2005) and Lemmon, Roberts, and Zender (2008) find that firm fixed effects have $R^{2}$ s above 0.500 in panel leverage ANOVAs. Variance decompositions in LRZ indicate that firmand year fixed effects account for $98 \%$ and $2 \%$ of the total explained variation in leverage. This dramatic contrast suggests that researchers should concentrate on explaining cross-firm differences in leverage.

We find that time-series variation in leverage is also systematically important, which implies a 
comparable need to understand time-varying determinants of leverage. Four findings support this view. First, significant firm-specific sources of time-series variation manifest in ANOVAs that allow firm-time interaction effects. Second, a short-panel problem with Compustat samples inflates the explanatory power of firm fixed effects. Third, the explanatory power of year fixed effects is understated by samples focused on the 1970s and later, which miss the wholesale abandonment of conservative leverage that occurred as firms borrowed to fund expansion during the booming post-war economy. Fourth, as section $\mathrm{V}$ documents, there is substantial and pervasive time-series variation in industry-median leverage, which Frank and Goyal (2009) report is the strongest known determinant of a firm's leverage.

In terms of the underlying economics, year fixed effects consider a narrow type of time variation: All firms have identical simultaneous shifts in expected leverage. They miss firm-specific sources of time variation in leverage as, e.g., with the evolution of investment opportunities. Because firm-specific variation washes out in large sample averages, firm-time interaction effects must be included if ANOVA models are to capture firm-specific sources of time variation in leverage.

Use of a purely additive specification - i.e., one that excludes interaction effects - is not a mandate of the data, even with one observation per cell, e.g., a single leverage observation per firm per year. Scheffé (1959, section 4.8) describes how to test for interactions with one observation per cell: Impose restrictions on admissible interactions so that degrees of freedom are not exhausted in the estimation. We apply this approach and analyze models in which interaction effects for a given firm are assumed constant within each decade. The choice of decade intervals reflects a need for degrees of freedom, not a judgment that firms change leverage once every 10 years.

The leverage tests in Table III indicate that firm-decade interaction effects are highly significant. The most basic tests compare model (1) in which firm dummies can differ for each decade with model (2) in which each firm has a time-invariant dummy. The table also reports $F$-tests for comparing models (4) and (5), which add year dummies to (1) and (2). In ANOVA terms, (5) is a two-way interaction-inclusive model and (4) is the nested (purely additive) model in which interaction effects are set to zero. Panel A reports results for the 24 DJIA firms, while panels B and C analyze the constant composition sample, 
firms listed 20-plus years, and the full Compustat sample. F-tests strongly reject the equivalence of models (4) and (5) - and of models (1) and (2), with p-values less than 0.0001 in all cases.

\section{Table III here}

In panel $\mathrm{B}$, the $R^{2}$ of 0.561 for the full-sample estimation of model (2) is close to the high $R^{2} \mathrm{~s}$ for firm fixed effects reported in prior studies. This strong explanatory power of firm dummies reflects the shortpanel feature of the Compustat population: Over half the firms in our full sample have nine or fewer years of data. With short-run stickiness in leverage, firm dummies capture a large portion of the variation for firms listed just a few years, thus inflating the $R^{2}$ averaged over the sample as a whole and overstating the explanatory power of firm fixed effects for leverage over long horizons.

Consistent with a nontrivial short-panel effect, the $R^{2}$ for model (2) in Panel A is 0.271 over the full 75-year period and climbs monotonically - eventually doubling to 0.543 - as the analysis period shortens to 20 years. Further evidence of a short-panel effect for model (2) is in panel B: The $R^{2} \mathrm{~s}$ are markedly higher for the full sample than for the constant composition sample (which has 50 years of data for all firms) and for firms listed 20-plus years. The same relative $R^{2}$ pattern arises in panel $\mathrm{C}$, which includes ancillary controls for leverage as in Rajan and Zingales (1995).

Table IV's variance decompositions indicate that time-series sources of leverage variation are systematically important. Firm-decade interactions account for between $37.8 \%$ and $41.4 \%$ of the total explained variation in the DJIA sample, the constant composition sample, and among firms listed 20-plus years. In the full sample, interaction effects account for $22.4 \%$ of the explained variation. This is smaller than in the other samples because, as noted above, more than half the firms have nine or fewer years of data. With so many firms having little or no ability to register cross-decade effects, it is all the more notable that interactions account for over one-fifth of the total explained variation in the full sample.

\section{Table IV here}

Table IV also shows that a nontrivial portion of the explanatory power attributed to firm fixed effects in additive models is due to suppression of interaction effects. With interactions suppressed, firm fixed effects account for $54.8 \%$ of the total explained variation in the DJIA sample, with the $\%$ due to 
firm main effects declining in absolute terms by $23.9 \%$ to $30.9 \%$ when interactions are allowed. For the other three samples, we find absolute declines of $31.8 \%, 36.3 \%$, and $22.0 \%$ in the $\%$ of explained variation attributed to firm fixed effects when interaction effects are allowed.

Time-series effects that are common-to-all-firms have substantial explanatory power. In purely additive specifications, such effects account for $45.2 \%$ of the explained variation in the DJIA sample (row 2 of Table IV) and $20.8 \%$ in the constant composition sample (row 4). The comparable figure in LRZ is 2\%. The large difference arises because their sample begins with 1965, while our constant composition sample goes back to 1950 and the DJIA sample goes back to the 1920 s.

In our first draft, we documented pervasive leverage increases by Compustat firms during the 1950s and 1960s, and this trend helps explain why common-to-all-firms effects are so strong in Table IV. For brevity, we exclude most details from the first draft and simply include Figure 2, which shows that Compustat firms engaged in wholesale abandonment of conservative leverage over the 1950s and 1960s. The increased incidence of low leverage firms in recent years (panel A) is due to a surge in listings by young growth firms that have little or no debt. The constant composition trend (panel B) thus offers a clearer picture of the wholesale abandonment of conservative leverage that played out after World War II. Taggart (1985, Table 1.1) and Graham, Leary, and Roberts (2013) also report a general post-war trend toward higher leverage, which supports our findings of significant year fixed effects.

Figure 2 here

Overall, our findings in this section indicate that (i) firm-specific time-series variation in leverage is systematically important, just as prior studies have reported for cross-firm variation, and (ii) commonto-all-firms time-series variation is also systematically important when the sample includes the post-war era, which saw many firms abandoning conservative leverage policies.

\section{How stable is the leverage cross section?}

To assess the stability of the cross section, we gauge the forecasting power of a given cross section for the sequence of future cross sections. Figure 3 reports average $R^{2}$ s that measure the extent to which firms with high (or low) leverage in a given cross section tend to have high (or low) leverage in the 
cross section $T$ years forward in time. For the constant composition sample (panel A) and the full sample (panel B), the vertical axis plots the average squared cross-sectional correlation coefficient over all pairs of cross sections that differ by $T$ years, the amount on the horizontal axis. Let $\rho(t, T)$ denote the crosssectional correlation between leverage in years $t$ and $t+T$. With 59 years in the sample (1950 to 2008), the number of correlations for a given $T$ is $N(T)=59-T$. Thus, the average squared correlation plotted on Figure 3's vertical axis, with T on the horizontal axis, is $R^{2}=\sum_{t=1}^{N(T)} \rho(t, T)^{2} / N(T)$.

Figure 3 here

Figure 3 shows that the average $R^{2}$ for adjacent-year leverage cross sections is around 0.8 in both samples, but declines to about 0.4 for cross sections five years apart and to almost 0.2 for cross-sections 10 years apart. Leverage cross sections that differ by 20 years have an average $R^{2}$ a bit below 0.1 , while those for longer horizons are lower but still (barely) positive. Thus, the short-run stability in the leverage cross-section fades strongly and almost disappears over long horizons. The small but still-positive longterm $R^{2}$ s are consistent with Table I's finding that stable leverage regimes do occur from time-to-time.

The striking finding in Figure 3 is that cross sections more than a few years apart differ markedly, with no tendency for those differences to stabilize or reverse. Instead, the similarities between cross sections erode as the time between them lengthens, and they approach near-zero levels in the long run.

The instability of the cross section stands out in bold relief in Table $\mathrm{V}$, which presents quartile decompositions of cross sections for firms listed 20-plus years. For this analysis, we first sort firms into four groups based on Debt/TA ratios in 1950. We track forward from this year of group formation (event year $t=0$ ) and record the fraction of firms still in the same quartile in $t=1,2, \ldots, 19$. We repeat the process for 1951 through 1989, treating each calendar year in turn as the initial event year and recording the fraction of firms that are in their formation-year quartile in each future year. [Quartile cut-offs are determined separately for each calendar year.] Columns (1) to (5) report the fraction of firms always in their initial quartile as of year $t$, while columns (6) to (10) report the fraction currently in their initial group. The table reports averages over the 40 samples that correspond to initial years 1950 to 1989 . 


\section{Table V here}

Migration of firms across quartiles of the cross section occurs pervasively. For the full sample, only 0.072 of firms always remain in their initial quartile group through year $t=19$ (column (1) of Table V). A remarkable 0.695 of the full sample are in three different quartiles at different times over the 20year period, while 0.304 spend time in all four. For the Low/Medium and Medium/High quartiles, a trivial 0.004 and 0.003 of firms fail to move to a new quartile ((3) and (4)). The Lowest and Highest quartiles show some persistence in group membership, with 0.163 and 0.117 of each initial group, or about $4.1 \%$ and $2.9 \%$ of the full sample, staying in the same quartile ((2) and (5)).

Persistent presence in a given quartile does not mean that a firm necessarily has stable leverage. It does reflect leverage stability for the typical firm always in the Lowest quartile, with the median such firm having a range in Debt/TA of 0.054 over the 20 years. However, because the Highest quartile is wider than the others, firms can (and do) show large variation in leverage while staying in that quartile. Among firms always in the Highest quartile, the median range in Debt/TA is 0.246, which indicates nontrivial leverage variation.

Table $\mathrm{V}$ shows a modest tendency for firms to revert back to their earlier quartile placements. If firms were allocated randomly to groups, then 0.250 would be the expected fraction of firms currently in their initial group. Thus, in columns (6) to (10), a decline from 1.000 to a fraction near 0.250 indicates no persistence in the sense of a greater than expected (under the null of random assignment) incidence of future quartile placements that match firms' initial placements. For firms initially in the Low/Medium and Medium/High groups, the fractions in those groups in year $t=19$ are 0.294 and 0.300 , or just 0.044 and 0.050 above the 0.250 expected under random assignment ((8) and (9)). The comparable fractions for the Lowest and Highest groups are 0.422 and 0.406 , or 0.172 and 0.156 above the fraction expected under random assignment ((7) and (10)). Among firms initially in the Lowest quartile, 0.632 are in the top two quartiles at some point (bottom panel of (2)), and 0.329 are in the top two quartiles at $t=19$, on average. Among those initially in the Highest leverage quartile, 0.646 spend time in the lowest two quartiles (bottom of (5)), and 0.333 are in lowest two quartiles at $t=19$. Hence, even for the extreme quartiles, 
there is a large migration of firms to the opposite side of the leverage cross section.

As evidence of stability of the cross section, Lemmon, Roberts, and Zender (2008, Figure 1) point to differences that remain after 20 years across the cross-sectional average leverage ratios of groups of firms sorted by quartile placement of current leverage. We confirm this finding for the partitioning in Table V: Group average leverage is $0.175,0.222,0.255$, and 0.304 in year $t=19$ for firms initially in the Lowest, Low/Medium, Medium/High, and Highest quartiles.

Drawing inferences about leverage stability from stable levels of (or stable differences in) crosssectional averages is problematic. The reason is that, with hundreds of firms in each group, averaging can - and, empirically, does - mask large time-series variation in leverage for firms in each group. ${ }^{2}$

Nor do the year $t=19$ averages establish the existence of permanent leverage components (or differences across groups in such components). Time-series variation in leverage for all firms can be fully transitory, yet manifest in significant and stable differences in cross-group average leverage ratios. To see why, consider a simple example in which zero debt is the permanent leverage target for all firms. Suppose also that there are two large groups of firms. Each firm uses debt only for transitory financing, i.e., it borrows when a funding need arises and then pays down debt and seeks to re-establish zero leverage. Firms in the first group tend to do larger amounts of transitory borrowing than those in the second group. Suppose also that random funding needs arrive independently. With the law of large numbers at work, the cross-sectional average leverage ratio of the first group will stabilize at a higher level than the (also positive and stable) cross-sectional average leverage ratio of the second group. Stable differences in average leverage persist even though all firms eschew debt on a permanent basis and have fluctuating amounts of transitory debt outstanding at different times.

The implication is that the year $t=19$ differences in the group averages do not establish that (i) firms have differences in permanent leverage components or that (ii) any firms seek to keep debt

\footnotetext{
${ }^{2}$ Frank and Goyal (2008) find little change since the 1950s in aggregate leverage ratios. The same reasoning given above indicates that leverage stability in an aggregate or sample-wide sense - as reflected in little time-series variation in full-sample medians, means, or weighted averages - can and, as our data show, does co-exist with wide variation in leverage at many individual firms and with substantial instability of the cross section.
} 
permanently in their capital structures. These averages are consistent with a much weaker statement: There is a modest tendency for leverage to remain in roughly the same zone over long horizons.

The bottom line, then is that the leverage cross section exhibits substantial instability, with shortrun stability fading strongly over five to 10 year horizons, and almost disappearing over longer horizons.

\section{Leverage targeting and instability of the cross section}

The instability of the cross section reported in Figure 3 raises questions about the empirical relevance of leverage targeting. Given the evaporating similarity of cross sections, could Miller's (1977) neutral-mutation view - no targets, random evolution - plausibly explain how leverage behaves over long horizons? What about the debate over whether estimated speeds of adjustment (SOAs) to target ratios are glacial or reasonably rapid? To what extent is either SOA view consistent with cross sections differing so much over time? Are stationary or time-varying target ratios more compatible with Figure 3? Could the instability of the cross section arise because firms have target zones, not specific target ratios $?^{3}$

The answers to these questions are far from obvious because we generally operate with intuition about local rates of adjustment toward a leverage target in response to a one-time shock. What is the cumulative effect of leverage adjustments when multiple shocks arrive over time and when firms engage in different forms of targeting? How far is it reasonable for firms to wander from their targets under different forms of targeting? Is there enough such wandering in a given targeting model to "scramble" the cross section as much as it is scrambled over time in the real data?

We address these questions using simulations that analyze the ability of each model type to generate leverage cross sections that conform to the instability in the real data. We use goodness-of-fit statistics to gauge how well each model replicates the real data in Figure 3.

\footnotetext{
${ }^{3}$ Fama and French $(2002,2012)$ conclude SOAs operate at a "snail's pace" (between $7 \%$ and $18 \%$ of the distance to target per year), and Hovakimian and Li (2011) concur. Flannery and Rangan (2006) conclude SOAs show markedly more "rapid" rebalancing (about one-third the distance to target per year). Huang and Ritter's (2009) best estimate of SOA is $17 \%$ per year. Chang and Dasgupta (2009) question whether any SOA findings are meaningful by showing that the estimated mean reversion in these types of studies could reflect random behavior. Flannery and Rangan (2006) conclude that time-varying target ratios do a better job than stationary targets in explaining leverage, while Lemmon, Roberts, and Zender (2008) conclude in favor of stationary targets. Target-zone models have a range of indifference and rebalancing incentives when leverage is outside the target zone, and are suggested by the findings of Graham and Harvey (2005), Fama and French (2005), and Leary and Roberts (2005). Welch (2004) concludes that firms do little or nothing to rebalance leverage toward a target.
} 


\section{A. $\quad$ Simulation methods}

As detailed in Appendix B, each candidate model that we simulate has assumptions about the cross-firm distribution of leverage targets, speeds of adjustment to target (denoted $\lambda$ ), stochastic variation in targets, and shock volatilities. The general structure of the simulation is as follows:

\begin{tabular}{|lc|}
\hline Simulated leverage for a given firm in year $t, L_{t}$, is governed by a & $L_{t}=\frac{e^{x_{t}}}{1+e^{x_{t}}}$ \\
logit transformation of an underlying state variable, $X_{t}$ & $X_{t}=\lambda \bar{X}+(1-\lambda)\left(X_{t-1}+\sigma \epsilon_{t}\right)$ \\
Underlying state-variable process, all parameters firm specific & $\lambda$ where $0.0 \leq \lambda \leq 1.0$ \\
Speed of adjustment (SOA) to target leverage ratio & $\bar{X}$ (varies across firms) \\
Target value stated in terms of the underlying state variable & $\epsilon_{t}$ \\
Random perturbation from a unit normal distribution & $\sigma$ \\
Volatility of time-series shocks to leverage & $\bar{X}_{t}=\delta X^{*}+(1-\delta)\left(\bar{X}_{t-1}+c ̧ \varepsilon_{t}\right)$ \\
\hline Target-generating process $(\delta=1$ for stationary target models) & $X^{*}($ differs across firms) \\
Mean of a given firm's target-leverage probability distribution & $\delta$ where $0.0 \leq \delta \leq 1.0$ \\
Speed at which target leverage reverts to $X^{*}$ & $\varepsilon_{t}$ (independent of $\left.\epsilon_{t}\right)$ \\
Random perturbation from a unit normal distribution & $c ̧$ \\
Volatility of target process & \\
\hline
\end{tabular}

For each model and specific values of $\lambda, \sigma, \delta$, and ç (see Appendix B), we generate and average over many simulated iterations of the leverage cross-section. In each case, we calculate:

- $\quad R M S E(20)$ and $R M S E(40)=$ the square roots of the mean squared error of the model's simulated $R^{2}$ values relative to the actual $R^{2}$ s (from Figure 3) over 20- and 40-year horizons.

- $\quad V E=$ Variation Error $=$ the sum of (i) the absolute value of the difference between the median simulated firm's time-series standard deviation of leverage and the median in the data $(0.088)$ plus (ii) the absolute value of the difference between the median simulated year's standard deviation of leverage and the median in the data (0.181).

We gauge the overall goodness of fit of each model (and underlying parameter combination) by the sum: $R M S E(20)+V E$. This sum gives credit to models that have lower root mean squared errors (RMSE) in matching Figure 3, while penalizing models that generate cross-sectional instability due to greater leverage volatility than exists in the real data. The lower the value of this sum, the better the fit, with a value of 0.000 indicating an exact match with the instability of the cross section over a 20-year horizon and with the time-series and cross-sectional variation in leverage.

Table VI reports RMSEs for the best-fitting model of each type, i.e. the RMSEs for the candidate model with specific parameters that yield the lowest value of $R M S E(20)+V E$. We next discuss Table VI's 
main findings together with Figures 4, 5, and 6, which illustrate those findings.

\section{Table VI here}

\section{B, $\quad$ Main findings of the simulations}

Random variation, no targets. The neutral-mutation model $(\lambda=0.00$ in Table VI and Figure 4$)$ does a terrible job replicating the instability of the cross section. In this model, leverage wanders randomly because $\lambda=0.00$ dictates that target-rebalancing motives are fully absent from the process that specifies how leverage adjusts in response to shocks that disturb leverage from its current level. We also find a poor ability to replicate the real data for two other ways of modeling random leverage behavior - a reflecting barrier process and an absorbing barrier process (see the Internet Appendix).

As Figure 4 shows, the neutral-mutation model generates far more persistence in the leverage cross-section than exists in the real data. This persistence arises because $\lambda=0.00$ implies that the subordinated process governing the evolution of leverage has a unit root, thus removing any systematic pressure on leverage to adjust up or down when shocks arrive.

Figure 4 here

Because of the unit root-induced persistence, the $\lambda=0.00$ model exhibits highly significant firm fixed and trivial year fixed effects in ANOVAs of model-generated leverage. The $R^{2}$ for firm fixed effects is $77.1 \%$, while the $R^{2}$ for year fixed effects is $1.0 \%$, which are not far from the empirical findings in prior studies (and for our full sample in Table III). The point here is not that the neutral-mutation model is empirically credible. It most surely is not credible, as Table VI and Figure 4 show.

The point is that significant firm fixed effects are readily generated by random leverage behavior, and therefore are not informative about the existence of leverage targets, permanent leverage components, or cross-firm differences in these elements of capital structure.

Our neutral mutation analysis does not rule out the possibility of a good match to Figure 3 from yet other models that posit purely random variation in leverage. However, our finding that few firms keep Debt/TA ratios consistently above 0.500 (see section I) is difficult to rationalize with empirically plausible forms of purely random variation. This finding instead points to ongoing pressure on firms to 
rebalance down from high leverage, which is present in all the other models we study.

Speed of adjustment to target. Panel A of Table VI reports goodness-of-fit statistics for models with SOA parameters from $\lambda=0.9$ (aggressive rebalancing to a stationary target ratio) down to $\lambda=0.1$ (weak rebalancing). Models with $\lambda=0.1$ or 0.2 have roughly equal ability to replicate the instability of the cross section, with both doing a respectable job. This observation led us to check whether a model with $\lambda=0.15$ replicates the real data better than these two models. The $\lambda=0.15$ model does better than both over 20 years, and almost as well as the $\lambda=0.1$ model over 40 years.

Models with more aggressive rebalancing incentives $(\lambda \geq 0.3)$ do not do a good job matching the instability of the cross section. ${ }^{4}$ This is apparent in Figure 4, which plots the model-generated analogs of Figure 3 for $\lambda=0.15$ and $\lambda=0.3$. With $\lambda=0.3$, there is too much persistence, as the model-generated $R^{2}$ profile bottoms out around 0.2 while the real data approach zero asymptotically. For $\lambda \geq 0.4$, the $R^{2}$ plots (see the Internet Appendix) are consistently higher than the already-too-high value for the $\lambda=0.3$ model, thus indicating even worse ability to replicate the real data.

In sum, our analysis supports the Fama and French (2002, 2012) and Hovakimian and Li (2011) view that SOAs are typically quite slow. Chang and Dasgupta (2009) criticize prior SOA studies on the grounds that their estimates of positive SOAs could simply be an artifact of random variation in leverage. Our Table VI findings indicate that random variation is not empirically credible, and that an SOA to target of around $15 \%$ per year does a good job replicating Figure 3.

Target zone models. With a target zone, each firm has a stationary target ratio, but there is no incentive to rebalance toward that ratio unless leverage falls outside a specified interval around the target. For example, a target zone of width 0.300 centered on a ratio of 0.400 indicates that (i) $\lambda=0.0$ for leverage between 0.250 and 0.550 , and (ii) $\lambda>0.0$ when leverage is below 0.250 or above 0.550 . Flexible zones have a relatively low SOA outside the target zone $(0.0<\lambda \leq 0.2)$, while inflexible zone models

\footnotetext{
${ }^{4}$ In our formulation, $\lambda$ is the assumed constant speed of adjustment (SOA) for the $X_{t}$ process. Since leverage, $L_{t}$, is a non-linear transformation of $X_{t}$, the $L$-based SOA is not constant. This does not change our interpretations, as there is a close quantitative connection between the two SOA measures. For example, in the $\lambda=0.3$ case in panel A of Table VI, the $L$-based SOA is always below 0.32 for $75 \%$ of the simulation firms, and never reaches 0.35 for the other $25 \%$. Thus, the rate at which firms adjust $L_{t}$ toward target is closely approximated by $\lambda=0.3$.
} 
have stronger rebalancing incentives $(\lambda \geq 0.5)$ when shocks move leverage outside the zone. Wide zones of both types are leverage intervals of size 0.300 , while narrow zones are intervals of 0.100 .

Flexible zone models do a good job replicating the instability of the cross section, as indicated by the RMSEs in panel B of Table VI. The width of the zone makes no real difference in terms of RMSE over the 20-year horizon, but wider zones have a lower RMSE over 40 years. Inflexible zone models do not perform nearly as well, and they do especially poorly when the target zone is narrow (panel C).

As detailed in the Internet Appendix, all four of these zone models generate more similarity over time in leverage cross-sections than is present in the real data. Inflexible zone models struggle to get the $R^{2}$ below 0.2 , whereas near-zero $R^{2}$ s characterize the real data over long horizons. As shown in Figure 5, the flexible wide zone model also generates $R^{2}$ s that are too high in the long run, but not egregiously so.

Figure 5 here

Time-varying target (TVT) ratios. Panel D of Table VI reports RMSEs for the two TVT models that yield the closest match to the data. They have an almost perfect VE match (column (3)) and their RMSE(20) values are a bit better than the best fits among the flexible zone and stationary target models (column (1)) and the same is true of the RMSE(40) value for the first TVT model (column (2)).

Why do these TVT models do such a good job? The answer in the first case is that the model generates very large time-series variation in target ratios, coupled with aggressive rebalancing incentives. The median range in target ratios is 0.336 over the first 20 years, which is almost as great as the model's median range in leverage of 0.392 . With $\mathrm{SOA}$ of $\lambda=0.8$, the model induces firms to aggressively chase target ratios that change a lot over time. The result is repeated scrambling of the cross section, rendering today's leverage a poor predictor of future leverage.

In the second case, the cross section becomes well scrambled over time in part because of leverage targets that change by nontrivial amounts, albeit less dramatically than for the first TVT model. The median range in target ratios over 20 years is 0.153 versus a median range in leverage of 0.381 . The other reason is that the SOA to target is only 0.2 , which means that firms tolerate wide deviations from targets that are themselves changing a nontrivial amount. In essence, the second TVT model is a hybrid 
of (i) the first TVT model, which has high target-ratio volatility, and (ii) a stationary-target model with slow SOA to the fixed target. Since the latter two models both do a good job replicating the instability of the cross section, it makes sense that a hybrid would also do well.

\section{The bottom line: What the simulations show}

The TVT models have the best goodness-of-fit measures $(R M S E(20)+V E)$ among the models we analyze. As we next detail, their overall goodness-of-fit measures fall well below the cutoffs at which studies normally reject a null hypothesis, which in this case is that the model matches real Figure 3. Moreover, head-to-head statistical comparisons indicate that the best TVT model (target means of 0.200 to 0.400 ) has a clear edge over the other models in Table VI.

The fractile values in Table VI's column (6) specify where a model's $R M S E(20)+V E$ value falls relative to the values obtained by bootstrapping firms' actual leverage observations to generate a distribution of analogous values for the real data. Higher fractile values correspond to more reliable rejection of the null for the particular model under analysis. The 0.393 and 0.535 fractile values for the TVT models indicate their fits are better than $60.7 \%$ and $46.5 \%$ of the analogous values for the real data, and so the null is far from rejected at conventional significance levels. For 13 of the 19 models in Table VI, the fractile values are far above the 0.999 cutoff, indicating null rejection at significance levels far below $0.1 \%$. The flexible zone and weak-rebalancing (low $\lambda$ ) models have fractile values much lower than these 13 models, but they are borderline for null rejection at conventional levels.

In head-to-head statistical comparisons, the TVT model with the best overall fit does better than all other models, as indicated by the $t$-statistics in column (7) of Table VI. These $t$-values assess the mean differences in goodness-of-fit measures (across the 50 replications of each model) between (i) the TVT model with target means of 0.200 to 0.400 and (ii) the particular model in the row in question. ${ }^{5}$ The only

\footnotetext{
${ }^{5}$ Specifically, we calculate the replication-by-replication difference between $R M S E(20)+V E$ for the model in question less $R M S E(20)+V E$ for the TVT model with target means of .200 to .400 . There are 50 replications of each, and so we have 50 values of this difference, which are independent because each replication is independent of the others and because they are randomly chosen for this difference calculation. Hence their mean is asymptotically normal and their standard deviation can be computed directly from the individual differences. The $t$-statistic is the sample mean divided by the standard deviation over the square root of 50 (due to independence).
} 
other model that is statistically close to the best fit is the other TVT model in panel D, with a $t$-value of 1.92. Among the other models, the only ones with $t$-values below 10.0 are the $\lambda=0.15$ and $\lambda=0.2$ stationary-target models and the flexible zone models. With $t$-values of 4.70 and higher, the latter four models are clearly statistically inferior to the TVT model with the best overall fit.

While the TVT models thus have a statistical edge over the flexible zone and $\lambda=0.15$ models, the (more important) economic-significance differential is not clear-cut. Note in particular that much of the advantage for the TVT models is due to better VE matches rather than lower RMSEs relative to the real data (compare columns (1), (2) and (3) of Table VI).

This view is reinforced by Figure 6, which contains the simulated versions of Figure 3 generated by the $\lambda=0.15$ model and by the first flexible zone and TVT models in Table VI. Yes, the initial impression is that the TVT model yields the best match to Figure 3. But a second look at Figure 6 and the magnitude of the RMSEs in Table VI indicates that the flexible zone and $\lambda=0.15$ models also do quite well. Comparison t-tests to evaluate the $\operatorname{RMSE}(20)$ differences show that the $\lambda=0.15$ model does not differ at conventional significance levels from the best TVT model ( $t$-value $=1.57)$. And the RMSE(20) differences between the flexible wide zone and TVT models are only marginally significant $(t$-value $=$ 2.05). The RMSE differences among these models are small compared to their dominance of models with (i) reasonably rapid SOAs $(\lambda \geq 0.3)$ toward stationary target ratios, (ii) target zones with relatively inflexible boundaries, and (iii) no targeting and random variation.

Figure 6 here

If forced to choose a "best" model, we would pick the TVT specification that has target means ranging from 0.200 to 0.400 . However, we believe that the most reasonable reading of the evidence is that this model and the $\lambda=0.15$ and flexible zone models all do a good job, with only second-order differences among them. We accordingly interpret our findings as narrowing the set of credible models of capital structure, but not as clearly identifying a single "best" model. We would instead emphasize that our findings imply that credible models eschew complete indifference to leverage and share the following common element: Targeting behavior of one form or another that assigns little or no weight to having a 
particular debt/equity mix.

\section{Industry-median leverage and time-varying target ratios}

Industry-median leverage ratios, which are often used as target proxies, vary markedly over time. Table VII shows that, for the median 4-digit SIC industry, the time-series range in (industry-median) Debt/TA is 0.414 , and the standard deviation is 0.110 (panel A). Despite the dampening effect of aggregation, the corresponding figures at the 2-digit level are also large: 0.319 and 0.075 . Industrydecade interaction effects are highly significant for all SIC levels (panel B). They account for almost half the explained variation at the 4- and 3-digit levels, and more than one-third at the 2-digit level (panel C).

Table VII here

The new findings here are that industry-specific time-series variation is large and comparable in importance to the (previously documented) cross-industry differences in leverage that exist at a point in time. The substantial time-series variation in industry-median leverage is consistent with target leverage ratios that change substantially over time.

Table VIII documents the behavior of Debt/TA and of four different estimates of target leverage ratios around departures (in event year $t=0$ ) from stable leverage regimes. Here, a stable regime is 10 or more consecutive years in which Debt/TA remains in a bandwidth of 0.100 . Debt/TA for the median firm increases by 0.077 (from 0.125 to 0.202 ) in year $t=0$ (row 1 ). This leverage increase is much larger than the contemporaneous change in the various target ratio estimates that are based on industry-median leverage and other previously identified leverage determinants (Rajan and Zingales (1995)). For example, target model 2, which includes industry leverage at the 4-digit level, has a change in the median target of only 0.003 (row 3), which is just $3.9 \%$ of the 0.077 increase in Debt/TA in $t=0$. Note that the median change in debt as a fraction of lagged assets is 0.091 (row 16), which is close to, but exceeds, the increase of 0.077 in the $D e b t / T A$ ratio.

\section{Table VIII here}

The latter comparison indicates that the median firm's large leverage increase was not an exogenous shock that disturbed leverage from an essentially fixed target that is determined in accord with 
any of the models analyzed in Table VIII. It was the result of a managerial choice to increase debt despite the absence of any sign of a systematic increase in the target. Since actual leverage is typically below estimated target before $t=0$, the large leverage increase in $t=0$ could be a chosen rebalancing action toward a fixed target. But if that is the case, we can infer that the target-adjustment process is very slow because all of these leverage adjustments came after stable leverage regimes lasting 10 or more years.

We find similar results when we compare changes in leverage and target estimates surrounding leverage peaks and troughs. For these comparisons, we follow the Table VIII template, but for brevity tabulate the findings in the Internet Appendix. For the median firm reaching its all-time peak leverage, Debt/TA increases by 0.109 (from 0.337 to 0.446 ) in the year of the peak. The largest increase in target leverage for that year is for model 2, but it is only 0.006 at the median, or $5.5 \%$ of the Debt/TA change. For the median firm departing from its all-time lowest leverage, Debt/TA increases by 0.121 , while the largest median target increase is 0.001 (for target model 3), which is less than $1 \%$ of the Debt/TA change. For peaks and troughs, the debt increases as a \% of lagged assets are large (0.108 and 0.089 respectively), indicating that the leverage changes are managerial choices, not exogenous shocks.

These comparisons indicate that, if time-varying targets are to explain leverage changes around peaks, troughs, and departures from stable leverage, there is a clear need to identify leverage determinants beyond those emphasized in the empirical literature.

Other data in Table VIII suggest that aspects of investment policy are likely to be important in this regard. For example, departures from stability are associated with an increase in the asset-growth rate from 0.080 to 0.128 at the median (row 13 ). This $60 \%$ increase is highly significant statistically, as is the increase in capital expenditures and the financing deficit (rows 14 and 15). These findings indicate a material association between departures from stability and raising debt (row 16) to fund expansion. [This is not a tautological result since firms can borrow to fund equity payouts, which is what pure rebalancing theories predict firms do with the proceeds from debt issuance.]

Peaks and troughs also exhibit an association between leverage changes and investment policy. Peaks are generally accompanied by significant declines in capital expenditures and earnings, and are 
typically followed by declines in asset-growth rates. In the year after a trough, firms generally show large increases in capital outlays and asset growth.

We also find that the funding of expansion pervasively underlies leverage decisions in case studies of the 24 DJIA firms with leverage data back to the 1920s and earlier. Our case summaries, which are in the Internet Appendix, reveal that leverage decisions sometimes also reflect financial flexibility concerns, rebalancing to lower leverage, imitation of rivals, stock-market timing, and the personal views of top executives. The connection between expansion and abandonment of conservative leverage during the booming post-war economy (see Figure 2) stands out in bold relief in the case studies.

Our findings of a significant association between leverage changes and company expansion are consistent with evidence in Harford, Klasa, and Walcott (2008) and Uysal (2011) on leverage and acquisitions, Mayer and Sussman (2004) and DeAngelo, DeAngelo, and Whited (2011) on leverage and investment spikes, and Denis and McKeon (2012) on proactive leverage changes.

\section{Summary and implications of the evidence}

Leverage cross sections more than a few years apart differ markedly, with differences growing not reverting or stabilizing - until there is almost no similarity with earlier cross sections. Migration over the cross section is substantial and pervasive, with $69.5 \%$ of firms listed at least two decades appearing in three or four different leverage quartiles over a typical 20-year period.

The instability in the leverage cross-section is most closely replicated in simulations by models with time varying target leverage ratios that change a lot over time. Other models that also do a good job matching the real data are those with (i) target zones with flexible boundaries that allow wide leverage variation, or (ii) speeds of adjustment to stationary target ratios of around $15 \%$ per year. The differences among these three models are not large enough to conclude that any one is definitively the "best." It is clear, however, that these models dominate formulations with more rapid target-rebalancing speeds, inflexible target zones, or the complete absence of targeting by firms coupled with random leverage variation, as in Miller's (1977) neutral-mutation view.

We also find that many firms have high and low leverage at different times, but very few keep 
debt-to-assets ratios consistently above 0.500 for long periods. Although substantial within-firm variation in book leverage, market leverage, and the net-debt ratio is the norm, episodes of leverage stability at individual firms do arise occasionally. Such stability occurs mainly at low leverage, and is virtually always temporary.

Industry-specific time-series variation in leverage is comparable in importance to cross-industry differences that exist at a point in time. However, changes in target ratio estimates based on industrymedian leverage and other previously identified determinants are typically tiny relative to the leverage changes around departures from stable leverage regimes as well as around leverage peaks and troughs.

Compustat-listed firms abandoned conservative capital structures en masse during the 1950s and 1960s, and case-based evidence indicates this is associated with funding of expansion during the booming post-war economy. Substantial increases in asset growth typically accompany the large leverage changes observed around departures from periods of stability.

These findings imply that credible theories of capital structure must be able to explain significant leverage instability, and they point to firm, industry, and market-wide time-varying factors as systematically important determinants. As we next discuss, the findings also provide evidence about existing theories and useful guidance about the structure of empirically viable potential theories.

Cross-firm and time-series variation in leverage. If leverage were stable over long horizons, then explaining cross-firm variation would be a major research puzzle, and time-series variation would be of minor interest. In fact, both types of leverage variation are systematically important, and the two issues are not separable. Although cross-firm variation is substantial at any given point in time, the cross section is far from stable over time. Therefore, development of theories that can explain the substantial timeseries variation in leverage at individual firms is not only important in its own right, but it is also essential to explain the (markedly different) cross-sectional distributions that prevail at different points in time.

Instability of the leverage cross section. A significant puzzle for theorists is to explain why the relative positions of firms in the leverage cross-section are sticky in the short run, but far from stable over horizons of more than a few years, with similarities between cross sections evaporating as the time 
between them lengthens. This strong empirical regularity suggests that the evolution of leverage mainly reflects transitory (not necessarily random) factors that generally out-weigh any tendency for leverage to converge to, or hover near, stable permanent components.

Stationary target ratios. The evaporation of commonalities between cross sections contradicts theories that predict that firms remain close to stationary (or near-stationary) target leverage ratios. This regularity does not rule out the existence of constant target ratios, but it does substantially narrow the set of stationary-target theories that are empirically credible. For example, it is consistent with the subset of theories in which a firm faces only small value losses (relative to adjustment costs) when leverage differs markedly from a constant target ratio (Fischer, Heinkel, and Zechner (1989)). Theories of this type arguably are not target ratio-driven in an empirically meaningful sense because they imply that a desire to keep leverage near a fixed ratio has little effect on behavior. In our judgment, such theories are best viewed as essentially equivalent to target zone theories (see below) because they posit only second-order value differences across a reasonably broad subset of leverage ratios.

Time-varying target ratios. Theories with time-varying targets can explain the wide-ranging leverage movements that occur at individual firms. They also have a statistical edge over flexible zone and weak rebalancing theories in their ability to replicate the instability of the cross section. They are not without problems, however, as there is much that we simply do not know about target determinants. For example, leverage changes around departures from stable regimes are typically much larger than changes in targets estimated from industry-median leverage and other previously identified determinants. The same is true for the leverage and estimated target-ratio changes surrounding leverage peaks and troughs.

Deleveraging and targeting behavior. Our evidence does not rule out distress costs and taxes as material influences on leverage. In fact, something akin to distress costs must encourage rebalancing downward from very high leverage, since we find that many firms have Debt/TA ratios above 0.500 at some point, but almost no firms keep Debt/TA consistently above 0.500 for long periods of time.

Target leverage zones/ranges. Our evidence is consistent with theories in which firms have target leverage zones with boundaries that represent "soft" or flexible limits on leverage (Graham and 
Harvey (2001), Fama and French (2005), and Leary and Roberts (2005)). Flexible target "ceiling" might be more descriptive than "zone," given that many firms have Debt/TA ratios below 0.100 at some point, while ratios above 0.700 are much less common, and it is rare to find firms with Debt/TA permanently above 0.500. The notion that firms put target caps on acceptable leverage is consistent with the importance that CFOs attach to maintaining a given credit rating (Graham and Harvey (2001)), and with firms' lower propensity to issue debt when borrowing is more likely to trigger a rating downgrade, or soon after a downgrade occurs (Kisgen (2006, 2009)).

Target zones versus neutral-mutation behavior. The key feature of target zone theories is that, over a subset of feasible ratios, the choice of leverage does not have first-order value consequences that provide strong incentives to keep leverage consistently close to a target ratio. This view hearkens back, of course, to Modigliani and Miller (1958). However, our point is not that the debt/equity mix is literally irrelevant or that leverage evolves randomly as a neutral mutation, as Miller (1977) conjectured. On the contrary, models with random leverage variation and no targeting responses by firms are clearly rejected by our data, as they do a poor job replicating the instability of the leverage cross section.

Rather, the basic point is: Leverage varies so widely at so many firms that it becomes hard to believe in large benefits from a particular level. It seems more plausible that, over a fairly wide range, leverage per se is of second-order import for firm valuation, so the main determinants of leverage are factors other than the benefits of adhering closely to a particular debt/equity mix. This view seems quite plausible given how well the instability of the cross section is matched by models with flexible target zones or with weak incentives to adjust leverage toward a constant target ratio. These models share the common element that firms feel little urgency to attain (or maintain) a particular leverage ratio.

The plausibility of target zone models draws further support from Graham and Harvey (2001), who find that $37 \%$ of CFOs say their firms have a "flexible target," 34\% say they have a "somewhat tight target or range," and 19\% say they have no target. Only 10\% say they have a "tight" target debt ratio, but it is unclear whether these managers (i) treat their nominally tight targets as rigid rules or as non-binding financial-planning guides, and (ii) how much they actually change (or violate) their tight targets. What is 
clear is that few managers say that keeping leverage close to a particular ratio is an important objective.

Is leverage determined as a residual? How can the following four statements all be true? (1) Firms adhere closely to target leverage ratios. (2) Lintner-style target payout ratios govern dividend distributions. (3) Managers are reluctant to cut dividends and to sell equity. (4) Firms require capital to fund investment, and they often obtain outside funds. Simply put, this system is over-determined, and all four statements cannot be descriptive. Something has to give. This inference is closely related to Lambrecht and Myers' (2012) conclusion that target-adjustment models for payout and capital structure cannot co-exist. Their reasoning is that a firm's budget constraint implies that a dynamic theory of payout and investment effectively dictates a dynamic theory of capital structure.

Empirically, "stylized facts" (2), (3), and (4) suggest that wide leverage variation could plausibly be a by-product of decisions about other time-varying components of financial policy. We are not claiming the debt/equity mix is a "pure residual" that is forced to adapt because investment, payout, and equity-issuance decisions are always more important. But (2), (3), and (4) have strong empirical support, and so there is reason to take seriously the hypothesis that the leverage time path is shaped by trade-offs between other financial policy objectives and desired adaptation to leverage targets. For example, perhaps investment, payout, and equity-issuance considerations govern the time path of leverage as long as the firm's debt/equity mix remains within a wide range allowed by a flexible target zone.

Funding investment and other time-varying determinants of leverage. Our reading of the data is that credible theories of capital structure will likely emphasize the funding of investment, e.g., as in Myers and Majluf (1984), but without the strict pecking order, and as in the Hennessy and Whited (2005) class of dynamic models. This conjecture would seem to merit further study given the empirical association between company expansion and departures from stable leverage regimes and the post-war abandonment of conservative leverage policies. Credible theories will almost surely include other timevarying factors such as credit-market conditions, stock-market timing, valuation disagreements between managers and investors, and managerial attitudes and social norms about debt.

Bottom line. Empirically credible theories of capital structure will likely include some form of 
leverage targeting. But it will be targeting that allows wide time-series variation in leverage, with little or no emphasis on staying near a particular debt/equity mix, e.g., as in theories that posit either large changes over time in target ratios, glacial speeds of adjustment toward stationary target ratios, or flexible target zones with slow rebalancing speeds when shocks move leverage outside the zone.

The unresolved issue, then, is which of two broad views of leverage targeting is more descriptive. The first view holds that a firm's leverage ratio matters at each point in time, but the specific way it matters changes a lot over time. In this case, the challenge for researchers is to identify the factors that generate substantial time-series volatility in target ratios. The second view holds that, over a reasonably wide range of values, a firm's specific leverage ratio is of second-order importance, and is therefore largely determined as a residual. The simplest such case would be that firms have target leverage zones with (i) leverage dynamics inside the zone driven by factors not directly related to leverage and (ii) rebalancing incentives that are operative when leverage falls outside the zone. In this case, the challenge is to identify factors (e.g., investment, payout, and capital-access considerations) that effectively dictate that leverage is determined as a residual except when it is outside the target zone. 
Figure 1

Leverage Ratios of General Motors, IBM, and Eastman Kodak: 1926 to 2008

Book leverage is the ratio of total book debt to total assets. Market leverage is total book debt divided by the sum of total book debt and the market value of common stock. Leverage data are from company annual reports, Moodys manuals, and Compustat. Market values are from CRSP.
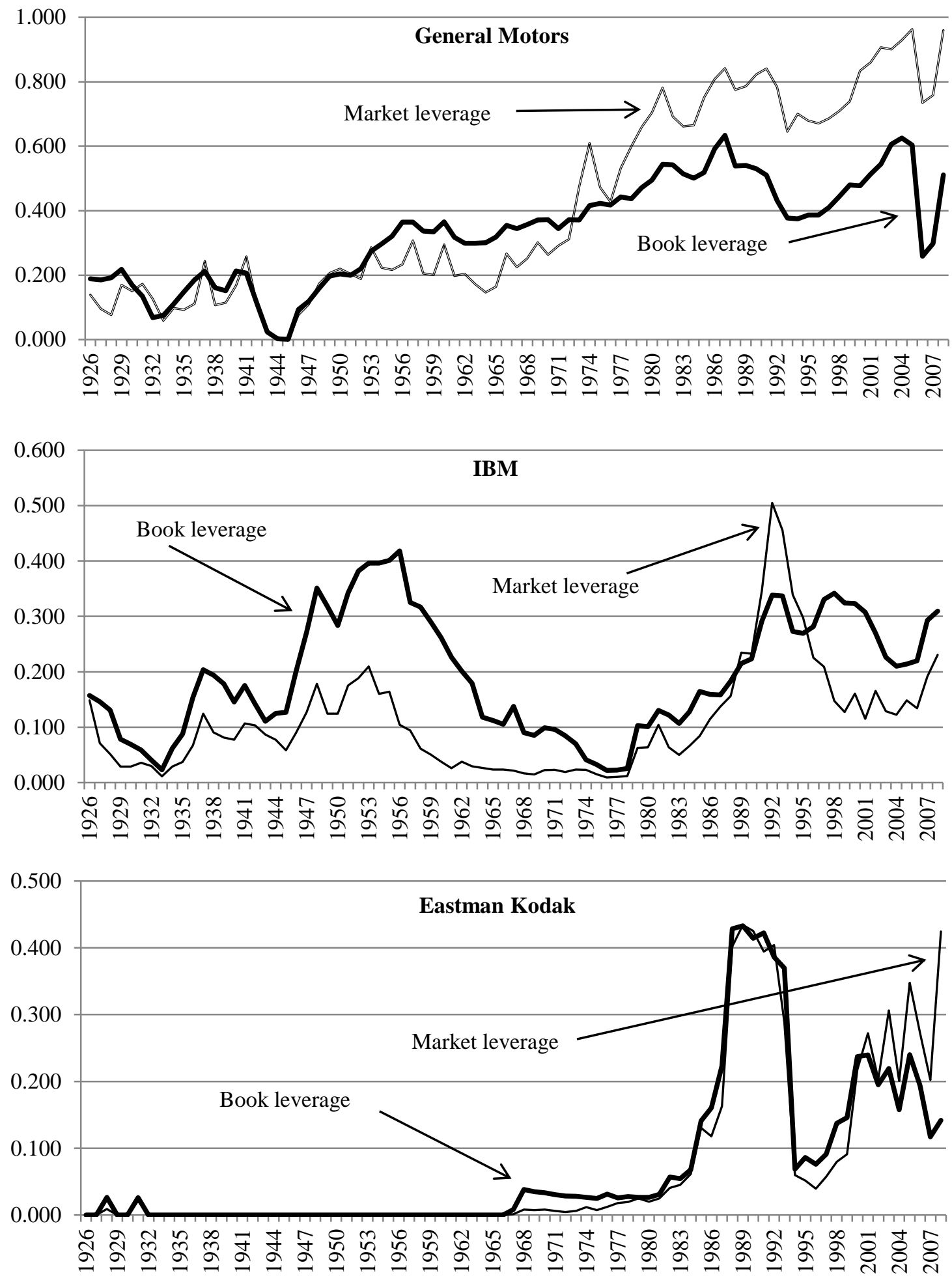
Figure 2

Conservatively Levered versus Highly Levered Publicly Held Industrial Firms: 1950 to 2008

Leverage is measured as the ratio of the book value of total debt to the book value of total assets (Debt/TA). The constituent firms in the full sample vary from year to year (per our sampling criteria). The constant composition sample contains the sub-sample of 157 firms with non-missing total assets on Compustat in 1950 that remained listed through at least 2000. The constant composition sample is unchanged over 1950 to 2000, but contracts over 2001 to 2008 due to the delisting of some firms. Conservatively levered firms are defined as those with no debt outstanding, while highly levered firms are defined as those with Debt/TA $>0.400$.

\section{A. Full sample incidence of conservatively levered and highly levered firms}

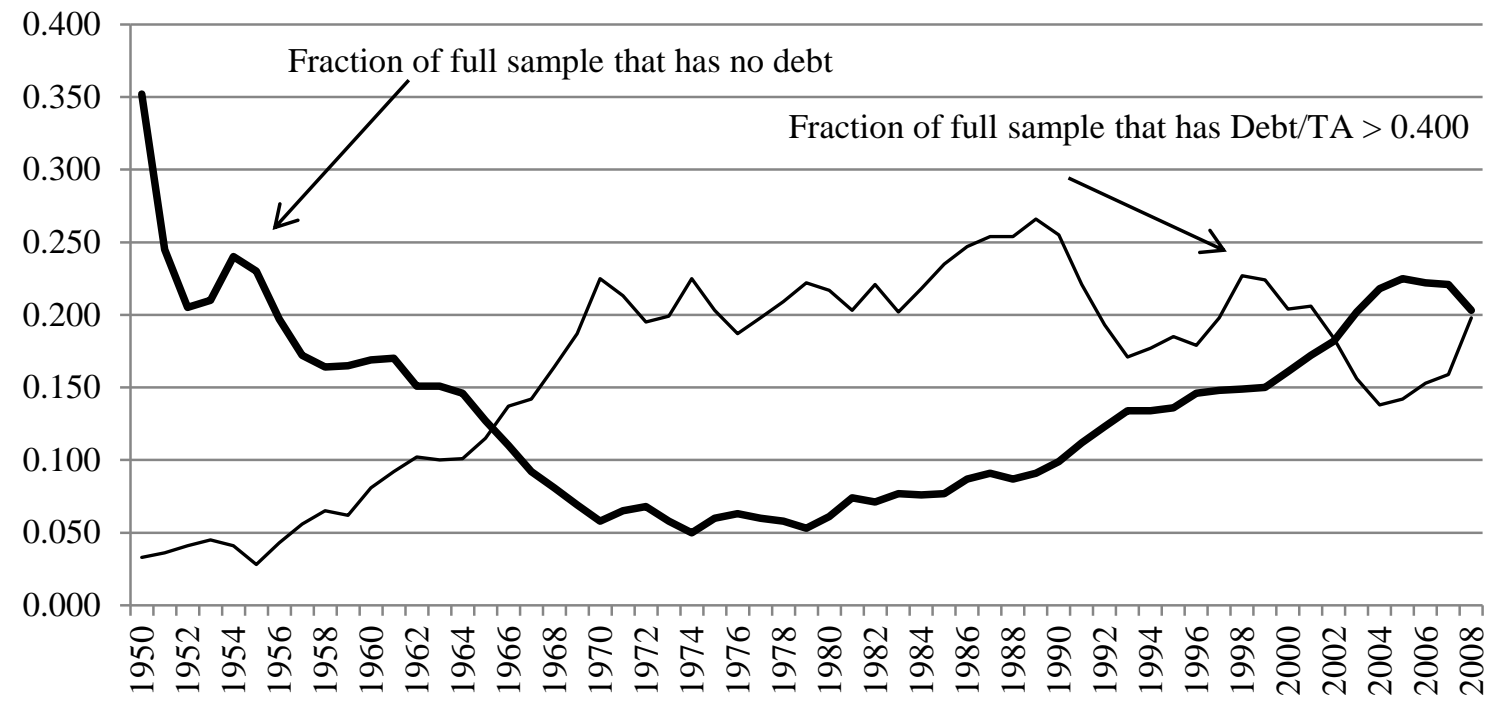

B. Constant composition sample incidence of conservatively levered and highly levered firms

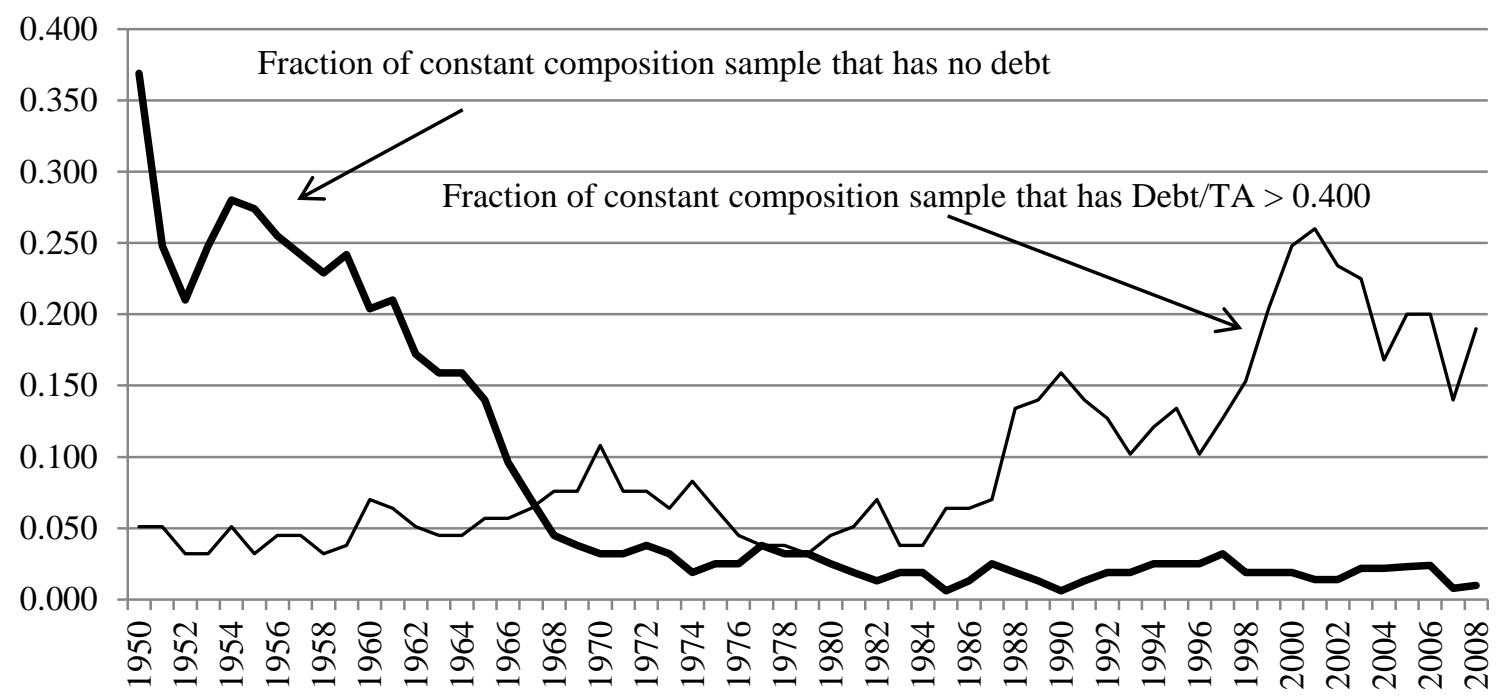


Figure 3

\section{Extent of Stability in the Cross Section of Leverage}

These figures present average $R^{2}$ s that measure the extent to which high (or low) leverage in a given year's leverage cross section corresponds to high (or low) leverage in future years' cross sections. Leverage is measured as the ratio of total debt to total assets in book value terms. Figure $3 \mathrm{~A}$ is based on the constant composition sample and Figure 3B is based on the full sample, with both using 59 years of data (1950 to 2008). The horizontal axis denotes the number of years between leverage cross sections. The vertical axis plots the average squared correlation coefficient over all pairings of sample years that differ by the amount specified on the horizontal axis. For example, to generate the average $R^{2}$ for the one-year difference in cross sections, we first identify all firms with leverage data in 1950 and 1951, and obtain the correlation between leverage in the two years. We repeat this process for 1951 and 1952 treated as a pair, then 1952 and 1953, and so on, and report in the figure the average $R^{2}$ across all pairings that differ by exactly one year. In general, to obtain the average $R^{2}$ for a $T$-year difference in cross sections, we repeat this process using the following pairs of years: 1950 and $(1950+T), 1951$ and $(1951+T), 1952$ and $(1952+T)$, and so on. Confidence intervals (two standard error bands in dashes) are obtained with a bootstrap procedure, re-sampling with replacement the individual squared correlations for each value of $T$ and using 1,000 sample replications.

\section{A. Constant composition sample: Average $\boldsymbol{R}^{2}$ versus number of years between leverage cross sections}

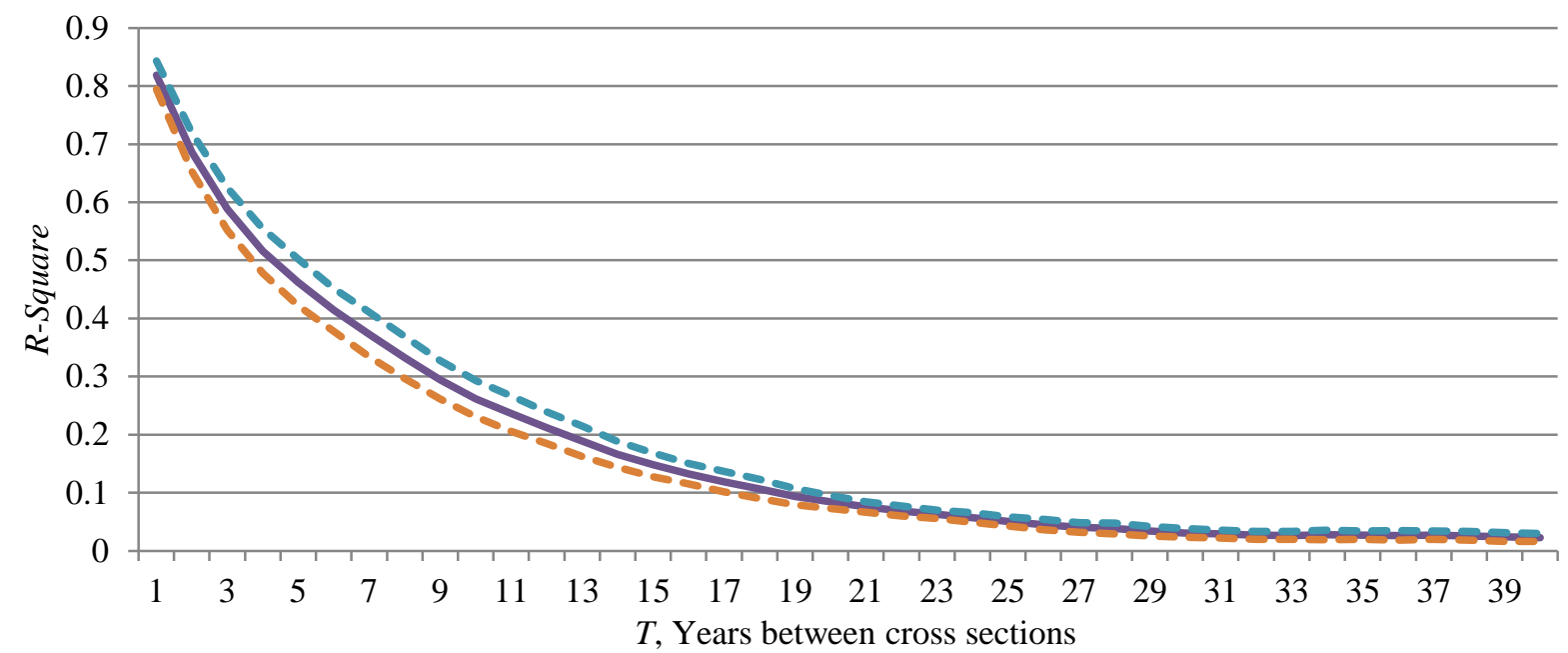

B. Full sample: Average $\boldsymbol{R}^{2}$ versus number of years between leverage cross sections

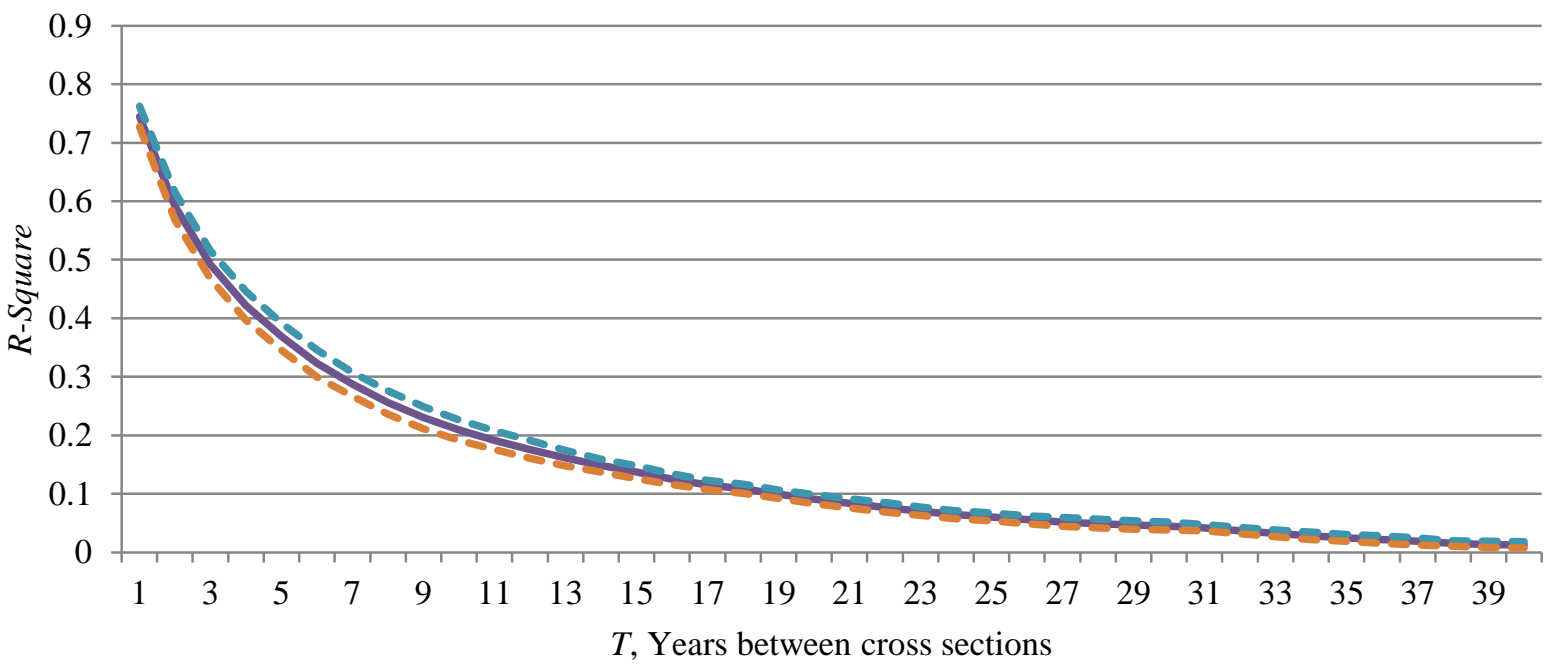




\section{Figure 4}

\section{Neutral-mutation and Stationary Target Leverage Ratio Models with SOA to Target of 0.3 and 0.15: Model-generated versus Actual Instability of the Leverage Cross Section}

The thick solid black plot is of the $R^{2}$ values for the relations between pairs of cross sections (for the full sample) in the real data, per Figure 3. The $\lambda=0.00$ plot is for a model with random variation in leverage and no targeting behavior by firms. The other plots are for the analogous $R^{2}$ s for the stationary target ratio models with $\lambda=0.3$ and $\lambda$ $=0.15$ in Panel A of Table VI. $\lambda$ denotes the speed of adjustment (SOA) to the target leverage ratio.

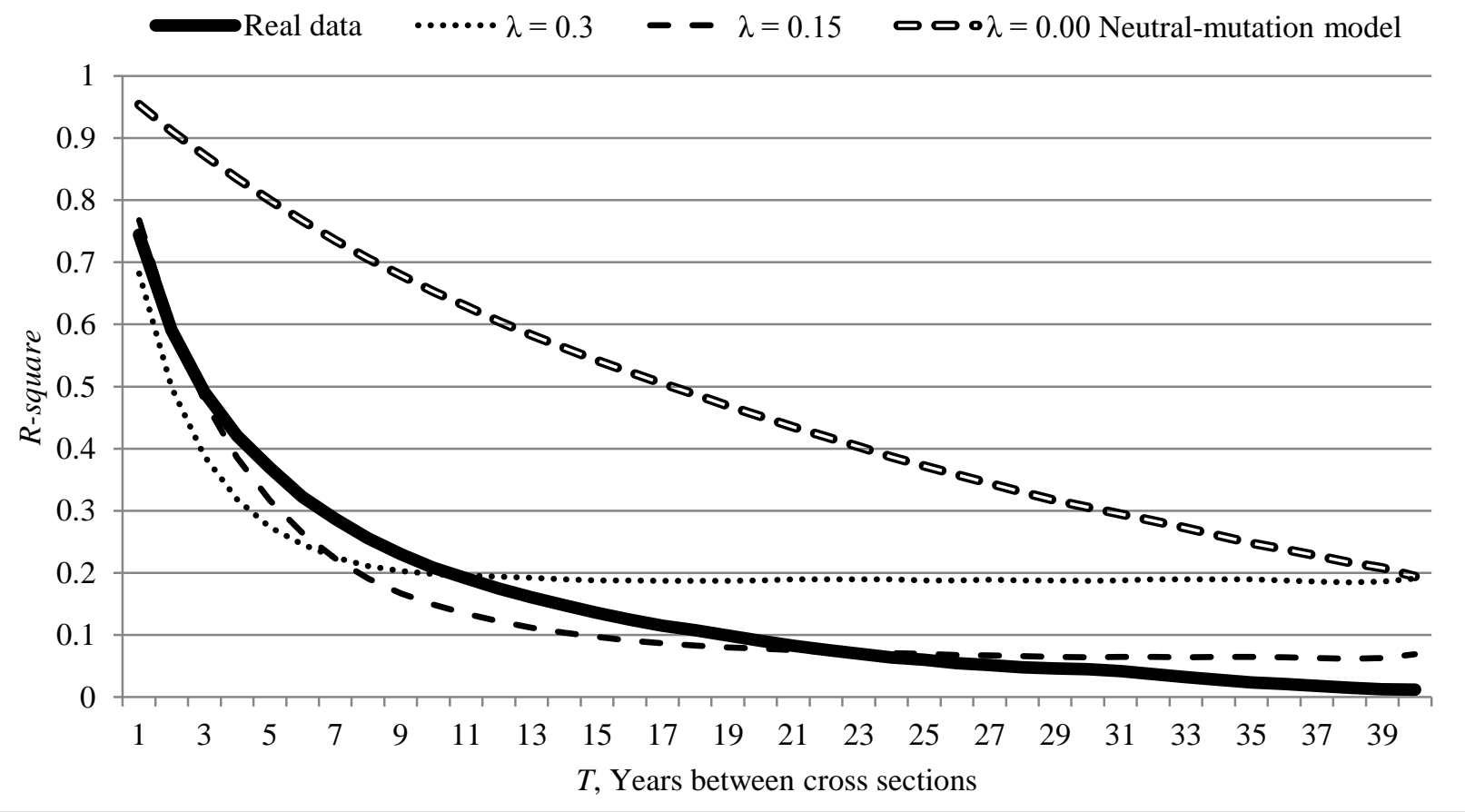




\section{Figure 5}

Target Zone Models with Flexible and Inflexible Boundaries: Model-generated versus Actual Instability of the Leverage Cross Section

The thick solid black plot is of the $R^{2}$ values for the relations between pairs of cross sections (for the full sample) in the real data, per Figure 3. The other plots are for the analogous $R^{2} \mathrm{~s}$ for the target zone models in Panels B and C of Table VI. The distinction between flexible and inflexible zone models is that, when leverage is outside the target zone, the latter have less aggressive speeds of adjustment back to the zone.

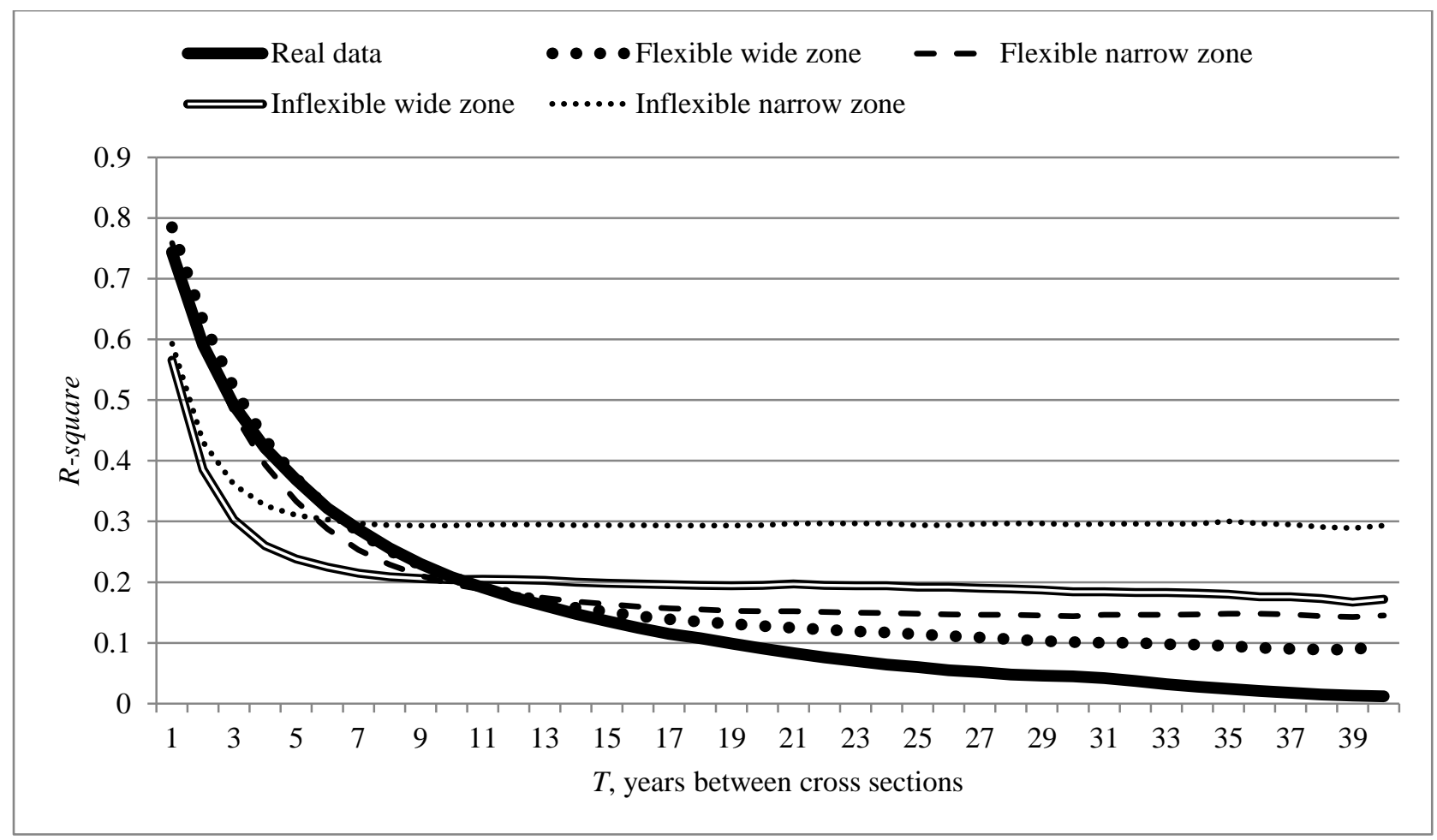


Figure 6

Model-generated versus Actual Instability of the Leverage Cross Section for the Best-fitting Stationary Target Ratio, Flexible Wide Zone, and Time-varying Target Models

The thick solid black plot is of the $R^{2}$ values for the relations between pairs of cross sections (for the full sample) in the real data, per Figure 3. The other plots are for the analogous $R^{2} \mathrm{~s}$ for the best-fitting stationary target ratio, flexible wide zone, and time-varying target models, per Table VI. The stationary target model has speed of adjustment (SOA) to target $=\lambda=0.15$. The flexible target zone model has width 0.300 . The time-varying target model has target means from 0.200 to 0.400 .

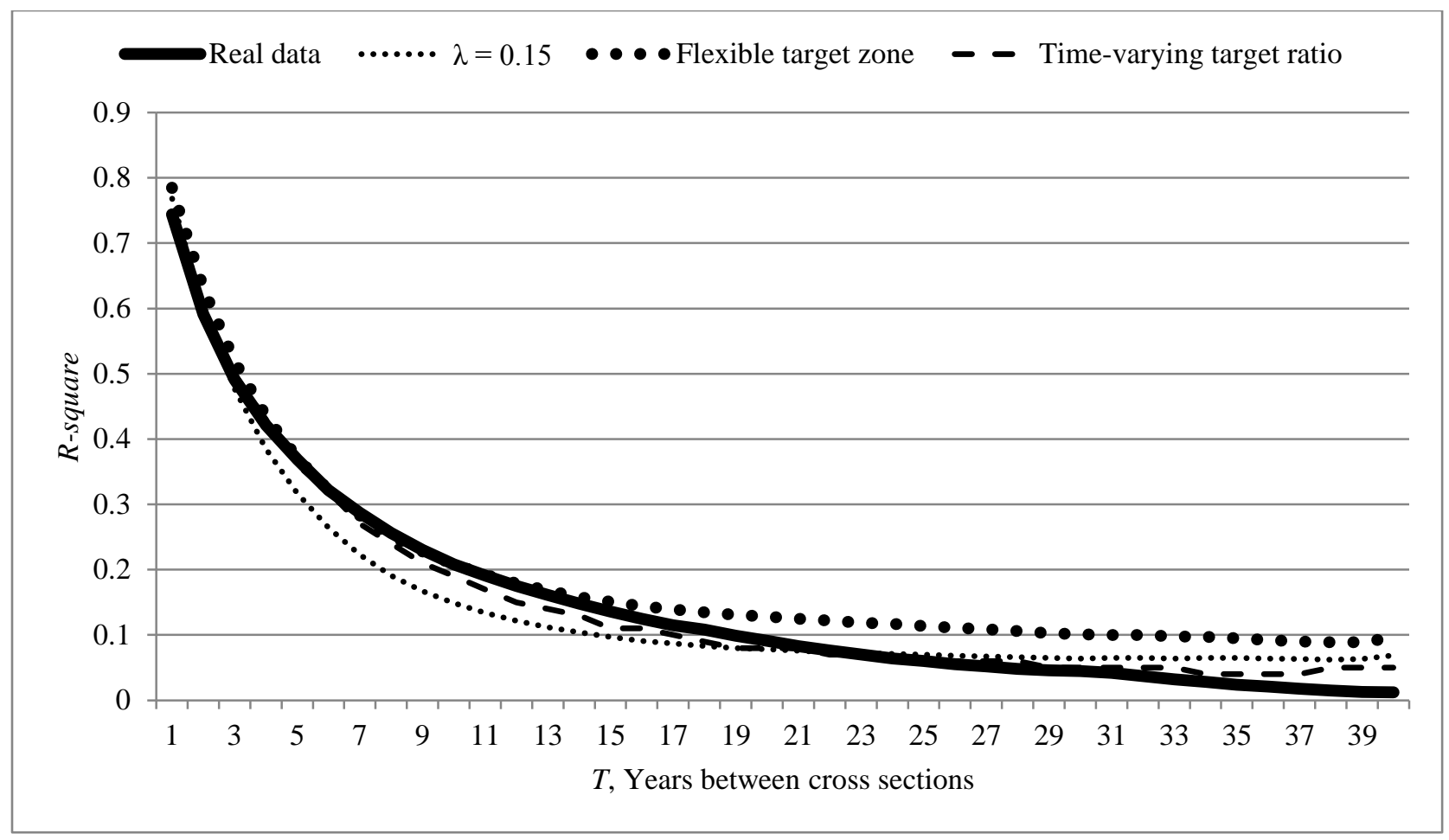


Table I

Time-Series Variation in Leverage

Book leverage is the ratio of total book debt to total book assets (Debt/TA). Market leverage is the ratio of book debt to the sum of book debt plus the market value of common stock. The net-debt ratio equals book debt minus cash, divided by total book assets. The sample contains 15,096 industrial firms in the CRSP/Compustat file over 1950 to 2008. The constant composition sample contains 157 firms that are included in the sample in 1950 and remain until at least 2000. Panel A excludes the $0.22 \%$ of firm-year observations with book leverage over 1.000 , and the $1.67 \%$ of firms with insufficient equity value data to measure the range of market leverage. The far right column gives the firm counts before these sample exclusions. In panel B, each row defines a stable leverage regime as one in which the firm's book leverage (Debt/TA) continuously remains in a range of values that differ by no more than a given amount $(0.050,0.100$, or 0.200 ). To generate the data in panel B, we first take a given firm and identify its longest stable leverage regime (based on each Debt/TA range specified in the rows). For example, to generate the data in the first row, we take a firm that has been listed at least 20 years and calculate the longest number of consecutive years that its $D e b t / T A$ ratio remained within a range of values that differ by no more than 0.050 . We repeat this process for all firms in the sample, and report the resulting histogram, with the sample median number of years given in the far-right column. n.m. indicates non-meaningful.

\section{A. Range, standard deviation, and level of leverage}

\begin{tabular}{|c|c|c|c|c|c|c|c|c|c|c|c|c|c|}
\hline \multirow[b]{2}{*}{ Years on Compustat } & \multicolumn{3}{|c|}{ Median range } & \multicolumn{3}{|c|}{ Median standard deviation } & \multicolumn{3}{|c|}{ Correlation (range, std dev) } & \multicolumn{3}{|c|}{ Median leverage ratio } & \multirow{2}{*}{$\begin{array}{c}\text { \# } \\
\text { firms }\end{array}$} \\
\hline & Book & Market & NetDebt & Book & Market & NetDebt & Book & Market & NetDebt & Book & Market & NetDebt & \\
\hline 20-plus & 0.391 & 0.536 & 0.599 & 0.106 & 0.144 & 0.153 & 0.926 & 0.944 & 0.925 & 0.211 & 0.221 & 0.135 & 2751 \\
\hline 15 to 19 & 0.357 & 0.462 & 0.574 & 0.106 & 0.136 & 0.161 & 0.957 & 0.966 & 0.957 & 0.195 & 0.167 & 0.098 & 1514 \\
\hline 10 to 14 & 0.314 & 0.393 & 0.527 & 0.098 & 0.124 & 0.156 & 0.968 & 0.973 & 0.967 & 0.189 & 0.159 & 0.086 & 2408 \\
\hline 5 to 9 & 0.241 & 0.294 & 0.424 & 0.084 & 0.104 & 0.145 & 0.982 & 0.985 & 0.978 & 0.179 & 0.128 & 0.071 & 3740 \\
\hline 2 to 4 & 0.110 & 0.117 & 0.250 & 0.049 & 0.053 & 0.109 & 0.990 & 0.991 & 0.987 & 0.173 & 0.098 & 0.038 & 3779 \\
\hline Constant comp sample & 0.400 & 0.507 & 0.624 & 0.106 & 0.128 & 0.153 & 0.859 & 0.943 & 0.882 & 0.208 & 0.219 & 0.140 & 157 \\
\hline
\end{tabular}

\section{B. Stable leverage regimes}

Firms listed at least 20 years:

$D e b t / T A$ range $\leq 0.050$

Debt/TA range $\leq 0.100$

Debt/TA range $\leq 0.200$

Constant composition sample:

Debt/TA range $\leq 0.050$

Debt/TA range $\leq 0.100$

Debt/TA range $\leq 0.200$
$\%$ of firms with Debt/TA continuously in specified range for at least: 10 years 20 years $\quad 30$ years 40 years $\quad$ longest stable regime

$\begin{array}{lllll}21.3 \% & 4.2 \% & \text { n.m. } & \text { n.m. } & 6.0\end{array}$

$\begin{array}{lllll}50.3 \% & 9.9 \% & \text { n.m. } & \text { n.m. } & 10.0\end{array}$

$\begin{array}{llll}85.7 \% & 36.9 \% & \text { n.m. } & \text { n.m. }\end{array}$

\begin{tabular}{|c|c|c|}
\hline $51.6 \%$ & $7.6 \%$ & $2.5 \%$ \\
\hline
\end{tabular}

$\begin{array}{lllll}94.9 \% & 28.0 \% & 7.6 \% & 1.3 \% & 16.0\end{array}$

$\begin{array}{lllll}100.0 \% & 87.9 \% & 51.0 \% & 14.6 \% & 30.0\end{array}$


Table II

\section{Stable Leverage Regimes and the Distribution of Firm-specific Maximum and Minimum Leverage Ratios}

In the first and second rows of panel A, we consider situations in which the firm's book-leverage ratio (Debt/Total Assets) continuously remains within a range no wider than 0.050 . In the third and fourth rows, we consider situations in which Debt/TA remains within a range no wider than 0.100 . The columns of panel A sort firms according to the median value of the Debt/TA ratio during its longest stable regime, and report the \% of firms (in the sample for the subject row) that falls within each leverage category. Panel B examines the 2,751 industrial firms listed on Compustat for at least 20 years over 1950 to 2008 . Rounding error explains the cases in which the \% in panel B do not sum exactly to the category total.

\section{A. Stable Leverage Regimes and the Level of Leverage}

\begin{tabular}{|c|c|c|c|c|c|c|}
\hline \multirow{4}{*}{$\begin{array}{c}\text { Debt/TA stays in specified bandwidth: } \\
\leq 0.050 \text { for } 20 \text { years } \\
\leq 0.050 \text { for } 10 \text { years }\end{array}$} & \multicolumn{5}{|c|}{$\%$ of firms with median Debt/TA during stable regime that falls in interval: } & \multirow{2}{*}{$\begin{array}{l}\text { Number } \\
\text { of firms }\end{array}$} \\
\hline & 0.100 or less & 0.100 to 0.200 & 0.200 to 0.300 & 0.300 to 0.400 & 0.400 or higher & \\
\hline & $100.0 \%$ & $0.0 \%$ & $0.0 \%$ & $0.0 \%$ & $0.0 \%$ & 115 \\
\hline & $88.8 \%$ & $3.6 \%$ & $3.3 \%$ & $2.1 \%$ & $2.1 \%$ & 994 \\
\hline$\leq 0.100$ for 20 years & $78.8 \%$ & $7.3 \%$ & $11.0 \%$ & $1.8 \%$ & $1.1 \%$ & 273 \\
\hline$\leq 0.100$ for 10 years & $62.2 \%$ & $11.5 \%$ & $12.9 \%$ & $7.2 \%$ & $6.2 \%$ & 2,158 \\
\hline
\end{tabular}

B. \% of Firms Listed 20 or More Years with Specified Combination of Maximum and Minimum Leverage Ratios

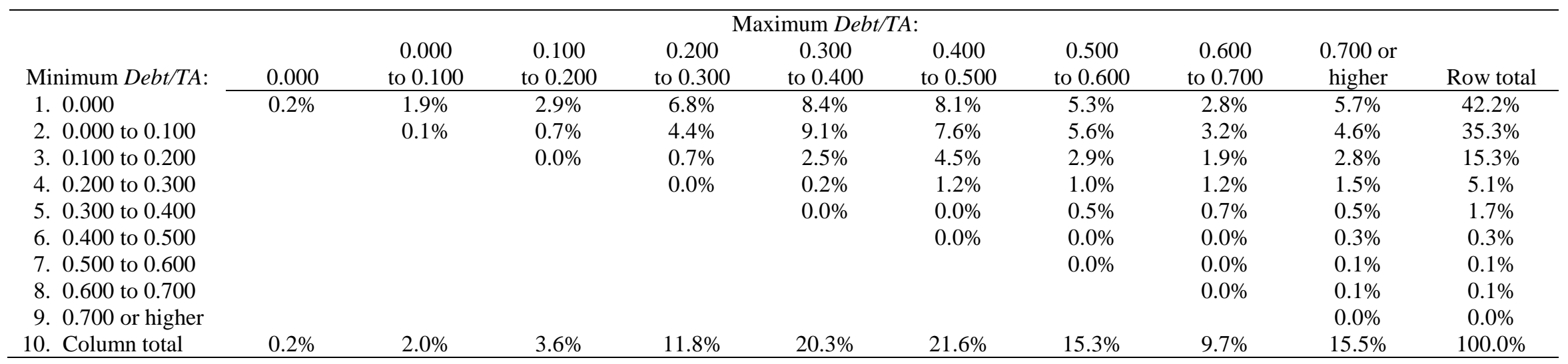


Table III

Explanatory Power of Firm and Year Main Effects and Firm-time Interaction Effects

The dependent variable is the ratio of debt to total assets $(D e b t / T A)_{\mathrm{jt}}$ where firms are indexed by $j$ and years are indexed by $t$. All $F$-statistics indicate significant differences at $p$-levels less than 0.0001 . The first $F$-statistic tests the hypothesis that model (1), which allows firm fixed effects to vary across decades, is indistinguishable from model (2) in which each firm has a dummy variable that remains constant over time. Models (4) and (5) differ from (1) and (2) by the inclusion of year dummies. Model (4) is the purely additive two-way specification that has only firm and year main effects. The additive model (4) is nested in the more general specification (5) that includes firm-time interaction effects, with interaction effects assumed constant within each decade. The $F$-statistic in the far right column gauges whether the firm-time interactions are significant, i.e., whether the general model (5) effectively reduces to the purely additive model (4). Panel A reports results for the 24 firms in the DJIA sub-sample, with data covering 1926 to 2000. The models in panel C differ from those in panels A and B by inclusion of other control variables often hypothesized to affect leverage decisions: Log (sales), Market-to-book ratio, EBITDA (profitability), and Asset tangibility. For the constant composition analysis, we work with the five decades from the 1950s through the 1990s. For the 20-plus year and full sample analysis, the initial year for a given firm can be later than 1950 and the last year can be as late as 2008. In models (2) and (4), the "firm dummy" variable for firm $j$ takes the value 1 for all observations corresponding to that firm, and the value 0 otherwise. In models (3), (4), and (5), the "year dummy" variable for year $t$ takes the value 1 if the observation is for year $t$, and 0 otherwise. In models (1) and (5), the "firm-decade" variables are decade-specific dummy variables for each firm. The first firm-decade dummy for firm $j$ takes the value 1 if the year falls in the first calendar decade in the estimation, and the value 0 if it falls outside that decade or if it corresponds to any other firm. The second firm-decade dummy for firm $j$ takes the value 1 if the year falls in the second decade of the estimation, and the value 0 if it falls outside that decade or if it corresponds to any other firm. And so on for firm-decade dummies corresponding to each subsequent decade for firm $j$. We exclude the $0.22 \%$ of observations with leverage above 1.00 . The results are statistically indistinguishable when leverage is truncated at 0.99 .

\begin{tabular}{|c|c|c|c|c|c|c|c|}
\hline & \multirow[b]{2}{*}{$\begin{array}{c}F \text {-statistic } \\
\text { to compare } \\
(1) \text { versus }(2)\end{array}$} & \multicolumn{5}{|c|}{ Adjusted- $R^{2}$ for model with: } & \multirow[b]{2}{*}{$\begin{array}{c}F \text {-statistic } \\
\text { to compare } \\
(4) \text { versus }(5)\end{array}$} \\
\hline & & $\begin{array}{c}\text { Firm-decade } \\
\text { dummies } \\
(1)\end{array}$ & $\begin{array}{c}\text { Firm } \\
\text { dummies } \\
(2)\end{array}$ & $\begin{array}{c}\text { Year } \\
\text { dummies } \\
(3)\end{array}$ & $\begin{array}{l}\text { Firm dummies } \\
\text { and } \\
\text { year dummies } \\
\text { (4) }\end{array}$ & $\begin{array}{c}\text { Firm-decade } \\
\text { dummies and } \\
\text { year dummies } \\
(5)\end{array}$ & \\
\hline \multicolumn{8}{|l|}{ A. Basic regressions: DJIA sample } \\
\hline 1926 to 2000 & 38.68 & 0.841 & 0.271 & 0.218 & 0.503 & 0.856 & 25.50 \\
\hline 1931 to 2000 & 38.88 & 0.836 & 0.291 & 0.212 & 0.518 & 0.851 & 25.48 \\
\hline 1941 to 2000 & 31.32 & 0.821 & 0.358 & 0.179 & 0.555 & 0.840 & 20.93 \\
\hline 1951 to 2000 & 23.15 & 0.810 & 0.461 & 0.104 & 0.588 & 0.832 & 17.79 \\
\hline 1961 to 2000 & 16.12 & 0.780 & 0.520 & 0.067 & 0.612 & 0.810 & 13.70 \\
\hline 1971 to 2000 & 13.87 & 0.761 & 0.544 & -0.007 & 0.560 & 0.774 & 13.83 \\
\hline 1981 to 2000 & 6.95 & 0.657 & 0.543 & -0.010 & 0.557 & 0.676 & 7.37 \\
\hline \multicolumn{8}{|l|}{ B. Basic regressions } \\
\hline Constant composition sample & 22.11 & 0.767 & 0.365 & 0.108 & 0.477 & 0.784 & 18.19 \\
\hline Firms listed 20-plus years & 9.92 & 0.709 & 0.471 & 0.030 & 0.496 & 0.717 & 9.53 \\
\hline Full sample & 5.99 & 0.697 & 0.561 & 0.028 & 0.574 & 0.704 & 5.87 \\
\hline \multicolumn{8}{|c|}{ C. Regressions with ancillary controls } \\
\hline Constant composition sample & 11.26 & 0.728 & 0.485 & 0.173 & 0.518 & 0.747 & 11.31 \\
\hline Firms listed 20-plus years & 8.26 & 0.719 & 0.523 & 0.115 & 0.532 & 0.727 & 8.40 \\
\hline Full sample & 5.70 & 0.730 & 0.610 & 0.121 & 0.616 & 0.735 & 5.72 \\
\hline
\end{tabular}




\section{Table IV}

\section{Relative Explanatory Power of \\ Firm Fixed Effects, Decade Fixed Effects, and Firm-Decade Interaction Effects}

The table presents variance decompositions for two-way ANOVA models that include firm fixed effects, decade fixed effects, and firm-decade interaction effects. We analyze balanced panels for both the 157 firms in the constant composition sample with data on Compustat from 1950 through at least 2000 , and for the 24 firms in the DJIA sub-sample with data back to at least 1926. For this balanced panel analysis, the DJIA sample runs from the 1930s to the 1990s, while the constant composition sample runs from the 1950s to the 1990s. We analyze an unbalanced panel for both the sample of 2,157 firms listed at least 20 years and for the full sample. The \%s in the table are the type III sum of squares explained by each given effect relative to the total explained by all effects included in the model. Because of computational limits with the full sample, we take 100 random samples of 1,510 firms (10\% of the total of 15,096 firms) and report the average over the 100 sample runs.

\begin{tabular}{|c|c|c|c|}
\hline & \multicolumn{3}{|c|}{$\%$ of explained variation accounted for by: } \\
\hline & $\begin{array}{c}\text { Firm-decade } \\
\text { interaction effects }\end{array}$ & $\begin{array}{c}\text { Firm } \\
\text { fixed effects }\end{array}$ & $\begin{array}{c}\text { Decade } \\
\text { fixed effects }\end{array}$ \\
\hline \multicolumn{4}{|l|}{ DJIA sample } \\
\hline 1. Interaction-inclusive model & $41.4 \%$ & $30.9 \%$ & $27.7 \%$ \\
\hline 2. Purely additive model & ---- & $54.8 \%$ & $45.2 \%$ \\
\hline \multicolumn{4}{|l|}{ Constant composition sample } \\
\hline 3. Interaction-inclusive model & $40.2 \%$ & $47.4 \%$ & $12.4 \%$ \\
\hline 4. Purely additive model & ---- & $79.2 \%$ & $20.8 \%$ \\
\hline \multicolumn{4}{|l|}{ Firms listed 20-plus years } \\
\hline 5. Interaction-inclusive model & $37.8 \%$ & $60.5 \%$ & $1.7 \%$ \\
\hline 6. Purely additive model & ---- & $96.8 \%$ & $3.2 \%$ \\
\hline \multicolumn{4}{|l|}{ Full sample } \\
\hline 7. Interaction-inclusive model & $22.4 \%$ & $76.8 \%$ & $0.8 \%$ \\
\hline 8. Purely additive model & ---- & $98.8 \%$ & $1.2 \%$ \\
\hline
\end{tabular}


Table V

Migration Over the Cross Section:

Fraction of Firms Always in and Currently in Their Initial Leverage Quartile

We start with calendar year 1950 and sort firms into four equal-sized groups based on their Debt/TA ratios in that year. We track forward from this year of group formation (event year $t=0$ ) and record the fraction of firms that remain in the same quartile group for event years $t=1,2, \ldots, 19$. We repeat the process for $1951,1952, \ldots, 1989$, treating each of these calendar years in turn as the initial event year and then noting the quartile location of each firm in each of the subsequent 19 years. In columns (1) to (5), we report the average over all 40 calculations of the fraction of firms that have remained in a given formation-year leverage group in every year up to the event year in question. For example, in column (1), the year $t=19$ entry of 0.072 indicates that an average of $7.2 \%$ of firms remain in the same quartile for 20 years. The sample composition does not change over each 20 -year period, and so the quartile cutoffs are not influenced by entry or exit of firms. [In each of the 40 initial-year groups that we form, we include the set of CRSP/Compustat industrial firms with leverage data available through at least the next 19 years.] In columns (6) to (10), we report the average over all 40 calculations of the fraction of firms that are currently in their formation-year leverage group in the event year (even though they may have left that group sometime after $t=0$ but before the current year). The rows at the bottom of the table give the fractions of firms in 4 different quartiles, at least 3 different quartiles, and at least 2 quartiles at different times over the 20 years.

\begin{tabular}{|c|c|c|c|c|c|c|c|c|c|c|}
\hline \multirow[b]{2}{*}{$\begin{array}{c}\text { Years } \\
\text { elapsed }\end{array}$} & \multicolumn{5}{|c|}{ Fraction of firms always in initial $(t=0)$ leverage quartile: } & \multicolumn{5}{|c|}{ Fraction of firms currently in initial $(t=0)$ leverage quartile: } \\
\hline & $\begin{array}{c}\text { Full } \\
\text { sample } \\
\text { (1) }\end{array}$ & $\begin{array}{c}\text { Lowest } \\
\text { leverage } \\
(2)\end{array}$ & $\begin{array}{c}\text { Low/Medium } \\
\text { leverage } \\
(3)\end{array}$ & $\begin{array}{l}\text { Medium/High } \\
\text { leverage } \\
(4)\end{array}$ & $\begin{array}{c}\text { Highest } \\
\text { leverage } \\
(5)\end{array}$ & $\begin{array}{c}\text { Full } \\
\text { sample } \\
\text { (6) }\end{array}$ & $\begin{array}{c}\text { Lowest } \\
\text { leverage } \\
(7)\end{array}$ & $\begin{array}{c}\text { Low/Medium } \\
\text { leverage } \\
(8)\end{array}$ & $\begin{array}{c}\text { Medium/High } \\
\text { leverage } \\
(9)\end{array}$ & $\begin{array}{c}\text { Highest } \\
\text { leverage } \\
(10)\end{array}$ \\
\hline $\mathbf{0}$ & 1.000 & 1.000 & 1.000 & 1.000 & 1.000 & 1.000 & 1.000 & 1.000 & 1.000 & 1.000 \\
\hline 1 & 0.720 & 0.829 & 0.638 & 0.617 & 0.796 & 0.720 & 0.829 & 0.638 & 0.617 & 0.796 \\
\hline 2 & 0.556 & 0.717 & 0.432 & 0.409 & 0.667 & 0.622 & 0.752 & 0.516 & 0.507 & 0.714 \\
\hline 3 & 0.450 & 0.637 & 0.304 & 0.284 & 0.573 & 0.570 & 0.705 & 0.461 & 0.451 & 0.663 \\
\hline 4 & 0.373 & 0.574 & 0.216 & 0.201 & 0.500 & 0.534 & 0.666 & 0.422 & 0.419 & 0.628 \\
\hline 5 & 0.315 & 0.521 & 0.153 & 0.142 & 0.443 & 0.505 & 0.631 & 0.391 & 0.395 & 0.603 \\
\hline 6 & 0.270 & 0.476 & 0.110 & 0.101 & 0.393 & 0.481 & 0.603 & 0.370 & 0.376 & 0.574 \\
\hline 7 & 0.235 & 0.436 & 0.078 & 0.071 & 0.353 & 0.464 & 0.582 & 0.353 & 0.365 & 0.557 \\
\hline 8 & 0.207 & 0.400 & 0.056 & 0.052 & 0.318 & 0.452 & 0.562 & 0.346 & 0.359 & 0.540 \\
\hline 9 & 0.185 & 0.369 & 0.041 & 0.040 & 0.290 & 0.439 & 0.545 & 0.336 & 0.350 & 0.525 \\
\hline 10 & 0.166 & 0.341 & 0.032 & 0.029 & 0.263 & 0.428 & 0.529 & 0.332 & 0.344 & 0.507 \\
\hline 11 & 0.150 & 0.316 & 0.024 & 0.022 & 0.239 & 0.417 & 0.513 & 0.327 & 0.338 & 0.491 \\
\hline 12 & 0.137 & 0.292 & 0.020 & 0.017 & 0.218 & 0.407 & 0.499 & 0.321 & 0.329 & 0.478 \\
\hline 13 & 0.125 & 0.270 & 0.016 & 0.013 & 0.199 & 0.397 & 0.482 & 0.317 & 0.324 & 0.465 \\
\hline 14 & 0.114 & 0.250 & 0.013 & 0.010 & 0.183 & 0.391 & 0.470 & 0.312 & 0.325 & 0.458 \\
\hline 15 & 0.104 & 0.230 & 0.010 & 0.008 & 0.168 & 0.380 & 0.457 & 0.308 & 0.312 & 0.442 \\
\hline 16 & 0.094 & 0.211 & 0.007 & 0.006 & 0.154 & 0.371 & 0.446 & 0.300 & 0.308 & 0.430 \\
\hline 17 & 0.086 & 0.193 & 0.006 & 0.005 & 0.140 & 0.364 & 0.436 & 0.295 & 0.304 & 0.423 \\
\hline 18 & 0.079 & 0.177 & 0.005 & 0.004 & 0.128 & 0.361 & 0.431 & 0.299 & 0.301 & 0.415 \\
\hline 19 & 0.072 & 0.163 & 0.004 & 0.003 & 0.117 & 0.355 & 0.422 & 0.294 & 0.300 & 0.406 \\
\hline \multicolumn{11}{|c|}{ Fraction of firms with leverage in 4,3 , or 2 different quartiles in different years: } \\
\hline 4 quartiles & 0.304 & 0.366 & 0.267 & 0.254 & 0.331 & --- & --- & --- & --- & --- \\
\hline at least 3 & 0.695 & 0.632 & 0.741 & 0.764 & 0.646 & --- & --- & --- & --- & --- \\
\hline at least 2 & 0.928 & 0.837 & 0.996 & 0.997 & 0.883 & --- & --- & --- & --- & --- \\
\hline
\end{tabular}


Table VI

\section{Alternative Models of Leverage Behavior and Instability of the Cross Section}

To gauge a model's goodness of fit, we take the square root of the mean squared error of (1) a model's $R^{2}$ values for comparisons of pairs of simulated cross-sectional "slices" versus (2) the $R^{2} \mathrm{~s}$ for the real data per Figure 3. $R M S E(20)$ and $R M S E(40)$ denote the root mean squared errors calculated over 20- and 40-year horizons. VE is a model's variation error. Columns (1) to (3) report RMSEs and VEs for the underlying parameter combination with the best overall fit, i.e., the lowest value of $R M S E(20)+V E$. Column (4) reports the lowest attainable RMSE(20) value regardless of $V E$. Column (5) reports the median firm's range in target leverage ratios over the first 20 years of the simulation. In column (6), higher fractile values correspond to more reliable statistical rejection of the simulation model. For example, a value of 0.950 would indicate that the simulation's fit is worse than all but $5 \%$ of the analogous values bootstrapped from the real data. Formally, (6) indicates where the model's goodness-of-fit measure $(R M S E(20)+V E)$ falls relative to the values obtained by bootstrapping firms' actual leverage observations to generate a distribution of goodness-of-fit measures based on the real data. Column (7) gives the $t$-statistic for the mean difference in goodness-of-fit measures (across the 50 sample replications) of the best model (see panel D) and the model specified in the row in question. $\lambda$ is the speed of adjustment toward a target leverage ratio. In panels B and $\mathrm{C}, \lambda=0.0$ when leverage is in the specified band around target $(+/-0.150$ for the wide range and $+/-0.050$ for the narrow range) and $\lambda>0.0$ when leverage is outside the band. "Flexible target zone" models have $\lambda \leq 0.2$ for leverage outside the band. "Inflexible target zone" models have $\lambda \geq 0.5$ for leverage outside the band. "Target means" refer to heterogeneity across firms in the means of the processes governing the evolution of target ratios. For example, " 0.100 to 0.400 " refers to a model in which a quarter of firms have targets drawn from a distribution with mean 0.100, another quarter have targets drawn from a distribution with mean 0.200 , etc. In panel $\mathrm{E}$, the reflecting barrier model assumes that leverage follows a Markov process, with no target and no path-dependent memory. Shocks that would hypothetically place leverage below 0.000 or above 1.000 instead reflect leverage back to the interior of the $[0.000,1.000]$ interval. In the absorbing barrier model, shocks that would hypothetically place leverage below 0.000 or above 1.000 instead leave leverage at the end point of the interval.

\begin{tabular}{|c|c|c|c|c|c|c|c|}
\hline & \multicolumn{3}{|c|}{$\begin{array}{c}\text { Lowest }(R M S E(20)+V E) \\
\text { of specified model type: }\end{array}$} & \multirow{2}{*}{$\begin{array}{c}\text { Lowest } \\
\text { attainable } \\
R M S E(20) \\
(4)\end{array}$} & \multirow{2}{*}{$\begin{array}{c}\text { Target } \\
\text { range } \\
(5)\end{array}$} & \multirow{2}{*}{$\begin{array}{l}\text { Model } \\
\text { fractile } \\
(6)\end{array}$} & \multirow{2}{*}{$\begin{array}{c}t \text {-statistic } \\
\text { for best fit } \\
\text { comparison } \\
(7)\end{array}$} \\
\hline & $\begin{array}{l}\operatorname{RMSE}(20) \\
(1)\end{array}$ & $\begin{array}{c}R M S E(40) \\
(2)\end{array}$ & $\begin{array}{l}V E \\
(3)\end{array}$ & & & & \\
\hline \multicolumn{8}{|l|}{ A. Stationary target ratios } \\
\hline $\mathrm{SOA}=\lambda=0.9$ & 0.229 & 0.310 & 0.172 & 0.229 & --- & $>0.999$ & 122.6 \\
\hline$\lambda=0.8$ & 0.161 & 0.182 & 0.080 & 0.161 & --- & $>0.999$ & 80.5 \\
\hline$\lambda=0.7$ & 0.160 & 0.222 & 0.022 & 0.149 & --- & $>0.999$ & 49.3 \\
\hline$\lambda=0.6$ & 0.138 & 0.188 & 0.028 & 0.136 & --- & $>0.999$ & 52.2 \\
\hline$\lambda=0.5$ & 0.135 & 0.205 & 0.016 & 0.123 & --- & $>0.999$ & 38.0 \\
\hline$\lambda=0.4$ & 0.116 & 0.187 & 0.014 & 0.101 & --- & $>0.999$ & 28.7 \\
\hline$\lambda=0.3$ & 0.072 & 0.118 & 0.021 & 0.072 & --- & $>0.999$ & 20.9 \\
\hline$\lambda=0.2$ & 0.039 & 0.080 & 0.011 & 0.036 & --- & 0.938 & 5.18 \\
\hline$\lambda=0.15$ & 0.033 & 0.048 & 0.016 & 0.030 & --- & 0.915 & 5.63 \\
\hline$\lambda=0.1$ & 0.048 & 0.039 & 0.028 & 0.045 & --- & $>0.999$ & 12.0 \\
\hline \multicolumn{8}{|l|}{ B. Flexible target zones } \\
\hline Wide zone $(0.300)$ & 0.033 & 0.054 & 0.028 & 0.033 & --- & 0.993 & 8.80 \\
\hline Narrow zone $(0.100)$ & 0.039 & 0.082 & 0.010 & 0.036 & --- & 0.915 & 4.70 \\
\hline \multicolumn{8}{|l|}{ C. Inflexible target zones } \\
\hline Wide zone $(0.300)$ & 0.108 & 0.128 & 0.026 & 0.039 & --- & $>0.999$ & 38.5 \\
\hline Narrow zone $(0.100)$ & 0.134 & 0.204 & 0.016 & 0.123 & --- & $>0.999$ & 43.7 \\
\hline \multicolumn{8}{|l|}{ D. Time-varying target ratios } \\
\hline Target Means 0.200 to 0.400 & 0.029 & 0.030 & 0.007 & 0.028 & 0.336 & 0.393 & Best fit \\
\hline Target Means 0.100 to 0.400 & 0.031 & 0.064 & 0.008 & 0.023 & 0.153 & 0.535 & 1.92 \\
\hline \multicolumn{8}{|l|}{ E. Random variation, no targets } \\
\hline$\lambda=0.00$ & 0.405 & 0.349 & 0.072 & 0.249 & --- & $>0.999$ & 44.6 \\
\hline Reflecting barrier model & 0.058 & 0.047 & 0.016 & 0.057 & --- & $>0.999$ & 11.4 \\
\hline Absorbing barrier model & 0.060 & 0.048 & 0.022 & 0.059 & --- & $>0.999$ & 13.9 \\
\hline
\end{tabular}




\section{Table VII}

\section{Industry-median Leverage: Time-series Variation, ANOVA Tests, and Variance Decompositions}

Industry-median leverage is the cross-sectional median value of Debt/Total Assets in a given year among all firms in a particular industry as defined by two-, three-, and four-digit SIC codes. Panels B and C follow the statistical methods in Table III and IV. In these panels, the dependent variable is the cross-sectional median Debt/TA ratio within each industry during each year from 1950 to 2008 inclusive. The $F$-statistics are all highly significant.

A. Time-series range and standard deviation of industry-median leverage

\begin{tabular}{lccc}
\hline Cross-sectional median of: & Four-digit SIC & Three-digit SIC & Two-digit SIC \\
\cline { 2 - 4 } Time-series range in industry-median leverage (Debt/TA) & 0.414 & 0.394 & 0.319 \\
Time-series standard deviation of industry-median leverage: & 0.110 & 0.104 & 0.075 \\
\hline
\end{tabular}

B. Explanatory power of industry and year main effect and industry-time interaction effects

\begin{tabular}{|c|c|c|c|c|c|c|c|}
\hline \multirow[b]{2}{*}{ Industry definition } & \multirow[b]{2}{*}{$\begin{array}{c}F \text {-statistic } \\
\text { to compare } \\
(1) \text { versus }(2)\end{array}$} & \multicolumn{5}{|c|}{ Adjusted- $R^{2}$ for model with: } & \multirow[b]{2}{*}{$\begin{array}{c}F \text {-statistic } \\
\text { to compare } \\
\text { (4) versus }(5)\end{array}$} \\
\hline & & $\begin{array}{c}\text { Industry-decade } \\
\text { dummies } \\
\text { (1) }\end{array}$ & $\begin{array}{l}\text { Industry } \\
\text { dummies } \\
\text { (2) }\end{array}$ & $\begin{array}{c}\text { Year } \\
\text { dummies } \\
(3)\end{array}$ & $\begin{array}{c}\text { Industry } \\
\text { dummies and } \\
\text { year dummies } \\
\text { (4) }\end{array}$ & $\begin{array}{c}\text { Industry-decade } \\
\text { dummies and } \\
\text { year dummies } \\
(5)\end{array}$ & \\
\hline Four-digit SIC & 7.95 & 0.619 & 0.352 & 0.040 & 0.385 & 0.629 & 7.50 \\
\hline Three-digit SIC & 10.11 & 0.641 & 0.330 & 0.064 & 0.384 & 0.652 & 9.07 \\
\hline Two-digit SIC & 15.26 & 0.747 & 0.428 & 0.072 & 0.506 & 0.766 & 13.31 \\
\hline
\end{tabular}

C. Variance decompositions: Industry fixed effects, decade fixed effects, and industry-decade interaction effects

\begin{tabular}{lccc}
\hline & $\begin{array}{c}\text { Industry-decade } \\
\text { interaction effects }\end{array}$ & $\begin{array}{c}\text { of explained variation accounted for by: } \\
\text { Industry } \\
\text { fixed effects }\end{array}$ & $\begin{array}{c}\text { Decade } \\
\text { fixed effects }\end{array}$ \\
\hline Four-digit SIC & $45.3 \%$ & $52.1 \%$ & $2.6 \%$ \\
Three-digit SIC & $46.3 \%$ & $48.1 \%$ & $5.7 \%$ \\
Two-digit SIC & $36.3 \%$ & $57.1 \%$ & $6.6 \%$ \\
\hline
\end{tabular}




\section{Table VIII}

\section{Target Leverage Variation and Departures from Stable Leverage Regimes}

The table presents the median values of Debt/Total Assets, four estimates of target leverage ratios, and various financial variables surrounding departures from the longest stable leverage regime for 945 firms listed 20 or more years on Compustat. For this analysis, a leverage regime is considered stable if the firm's Debt/TA ratio takes values that differ by no more than 0.100 for 10 or more consecutive years. For each such firm, the last year of its stable regime is designated event year -1 so that event year 0 is the year of its departure from stability, and all other event years over $t=-3$ to $t=3$ are defined analogously. With Target model 1 , the target leverage ratio of a firm is estimated as the fitted value from a regression (using the full sample) of Debt/TA on the four Rajan and Zingales (1995) variables specified in rows 9 to 12. For Target models 2, 3, and 4, we generate target ratio estimates in similar fashion. The only difference is that industry-median leverage (at respectively the 4-digit, 3-digit, or 2-digit SIC level) is included as an explanatory variable along with the determinants used for Target model 1 . The firm under analysis is excluded from the calculation generating industry-median leverage. If there are no other firms in the same 4-digit (3-digit) industry, we use the 3-digit (2-digit) industry-median leverage ratio instead. Asset growth equals assets in event year $t$ minus assets in year $t-1$, all divided by assets in $t-1$. The same divisor is applied to the year $t$ Capital expenditures, Financing deficit, Change in debt, and EBITDA. For Tangible assets in year $t$, we divide by total assets in year $t$. The financing deficit measures the amount of external financing net of distributions in a given year and equals the sum of net equity issues and net debt issues. [A negative financing deficit (i.e., a financing surplus) indicates that, on net, the firm does not raise outside funds in the period under consideration.] We employ the change in total debt outstanding as the measure of net debt issues to avoid sample-size shrinkage because of missing values on Compustat of the latter variable. For inclusion in this table, firms must be listed on Compustat through year $t=3$ relative to its departure from a stable leverage regime in year $t=0$. The variables in rows 9 to 16 are Winsorized at the $1 \%$ level. We use $* * *$ and $* *$ to identify significant differences at the 0.001 and 0.01 levels or better for Wilcoxon tests that compare the $t=0$ median value of a variable and its $t=-1$ value. The variables in rows 2 to 12 show no significant differences at the 0.10 level.

\begin{tabular}{|c|c|c|c|c|c|c|c|}
\hline \multirow[b]{2}{*}{ Median value of } & \multicolumn{7}{|c|}{ Event year relative to departure in year 0 from stable leverage regime: } \\
\hline & -3 & -2 & -1 & 0 & 1 & 2 & 3 \\
\hline 1. Debt/Total Assets & 0.120 & 0.125 & 0.125 & $0.202 * * *$ & 0.208 & 0.220 & 0.219 \\
\hline 2. Target model 1 & 0.252 & 0.254 & 0.252 & 0.255 & 0.259 & 0.260 & 0.258 \\
\hline 3. Target model 2 & 0.253 & 0.252 & 0.253 & 0.256 & 0.259 & 0.261 & 0.260 \\
\hline 4. Target model 3 & 0.253 & 0.250 & 0.254 & 0.257 & 0.259 & 0.260 & 0.259 \\
\hline 5. Target model 4 & 0.255 & 0.253 & 0.257 & 0.257 & 0.259 & 0.261 & 0.261 \\
\hline 6. Ind-median 4-digit & 0.209 & 0.211 & 0.213 & 0.221 & 0.223 & 0.224 & 0.221 \\
\hline 7. Ind-median 3 digit & 0.214 & 0.211 & 0.214 & 0.219 & 0.220 & 0.221 & 0.224 \\
\hline 8. Ind-median 2 digit & 0.208 & 0.211 & 0.215 & 0.216 & 0.218 & 0.219 & 0.221 \\
\hline 9. EBITDA & 0.169 & 0.166 & 0.164 & 0.167 & 0.158 & 0.156 & 0.151 \\
\hline 10. Log (Sales) & 5.544 & 5.644 & 5.677 & 5.780 & 5.880 & 5.983 & 6.073 \\
\hline 11. Market-to-book & 1.167 & 1.183 & 1.166 & 1.169 & 1.178 & 1.167 & 1.140 \\
\hline 12. Tangible assets & 0.315 & 0.315 & 0.319 & 0.326 & 0.329 & 0.325 & 0.320 \\
\hline 13. Asset growth & 0.076 & 0.071 & 0.080 & $0.128 * * *$ & 0.075 & 0.068 & 0.067 \\
\hline 14. Capital expenditures & 0.063 & 0.063 & 0.065 & $0.071 * *$ & 0.063 & 0.058 & 0.059 \\
\hline 15. Financing deficit & 0.004 & 0.001 & 0.002 & $0.069 * * *$ & 0.006 & 0.002 & -0.002 \\
\hline 16. Change in debt & 0.000 & 0.000 & 0.004 & $0.091 * * *$ & 0.005 & 0.002 & 0.000 \\
\hline
\end{tabular}




\section{Appendix A. Debt/Total Assets Ratios for 24 Dow Jones Industrial Average (DJIA) Firms}

Case details are in the Internet Appendix. All 24 firms are members of our constant composition sample, which means they are included on Compustat from 1950 to 2000. All 24 also (i) were publicly held prior to the Great Depression, (ii) issued annual reports back to at least 1926 with clearly delineated financial debt amounts, and (iii) were included in the Dow Jones Industrial Average (DJIA) at some point. For each firm, we track leverage back to 1900 if possible, but more generally as far back as annual report disclosures clearly separate financial debt from other liabilities (e.g., notes payable versus accounts payable). In cases in which firms had major financial subsidiaries whose debt obligations in some years were not consolidated with the parent, we obtain whatever financial data for the subsidiaries are provided in company disclosures and report estimated leverage ratios based on our construction of the relevant consolidated balance sheets. The latter firms are AT\&T, Caterpillar, General Electric, General Motors, Goodrich, Goodyear, IBM, Kodak, International Harvester (Navistar), Altria (Philip Morris), Sears Roebuck, Texaco, and Union Carbide. Two firms have financial subsidiaries whose operations are too small to merit disclosure (Coca-Cola) or the information that is disclosed is insufficient to estimate the leverage of the consolidated entity (U.S. Steel).

The date of the first (and sometimes the last) observation differs across companies, and so one must be careful in scanning across firms to be sure that one is comparing leverage in the same year. Since leverage ranges vary substantially, the scale of the vertical axis also differs across firms.
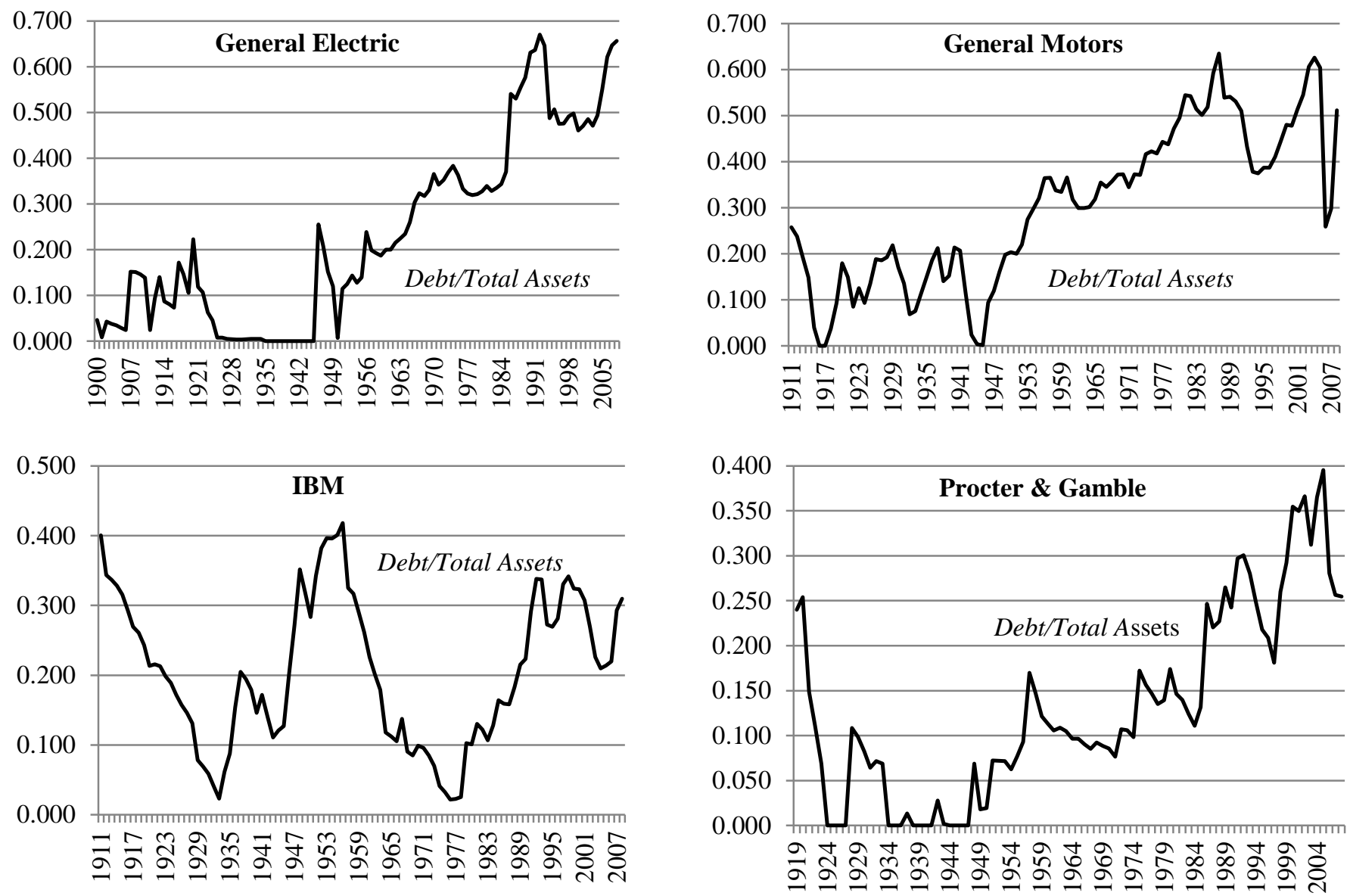

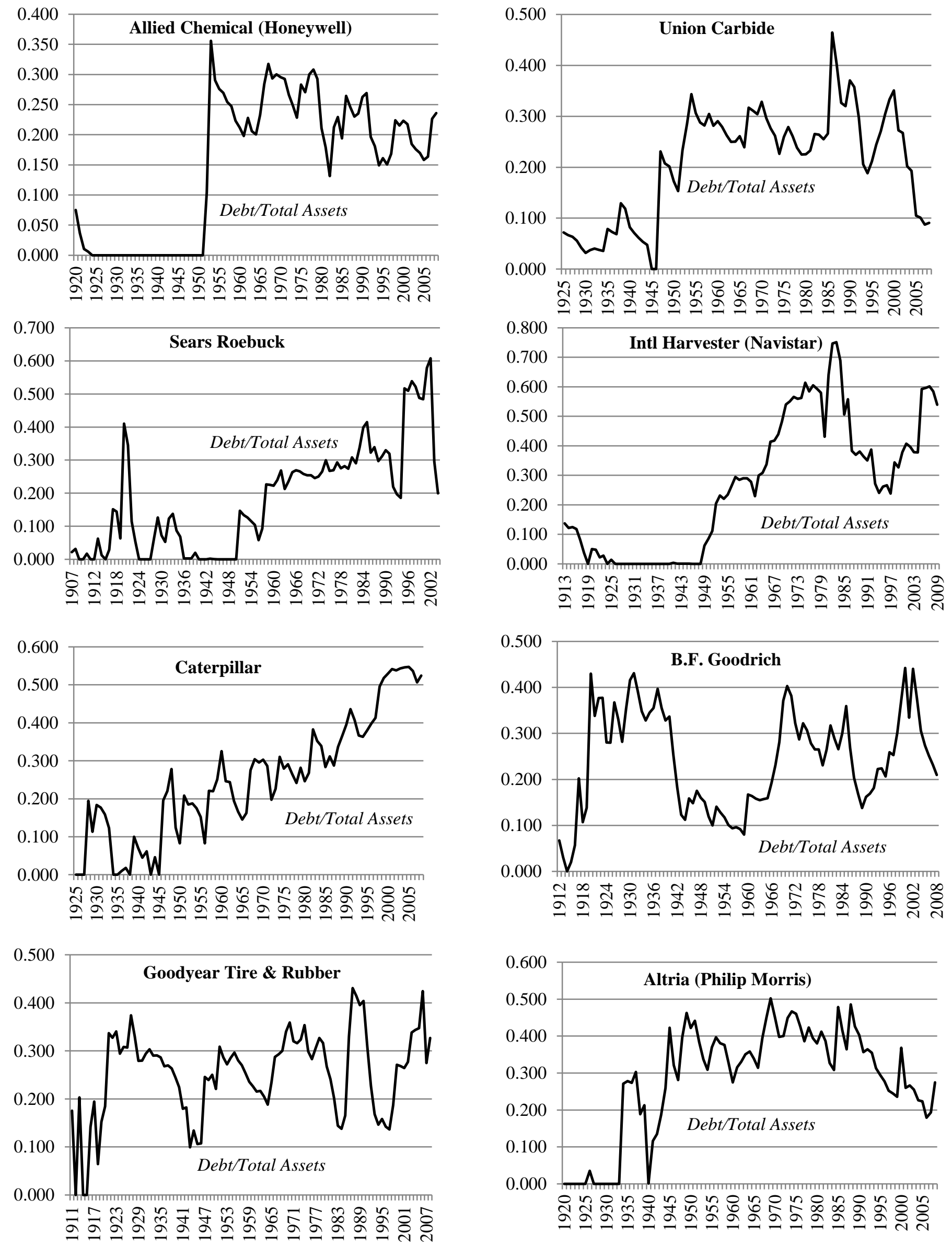

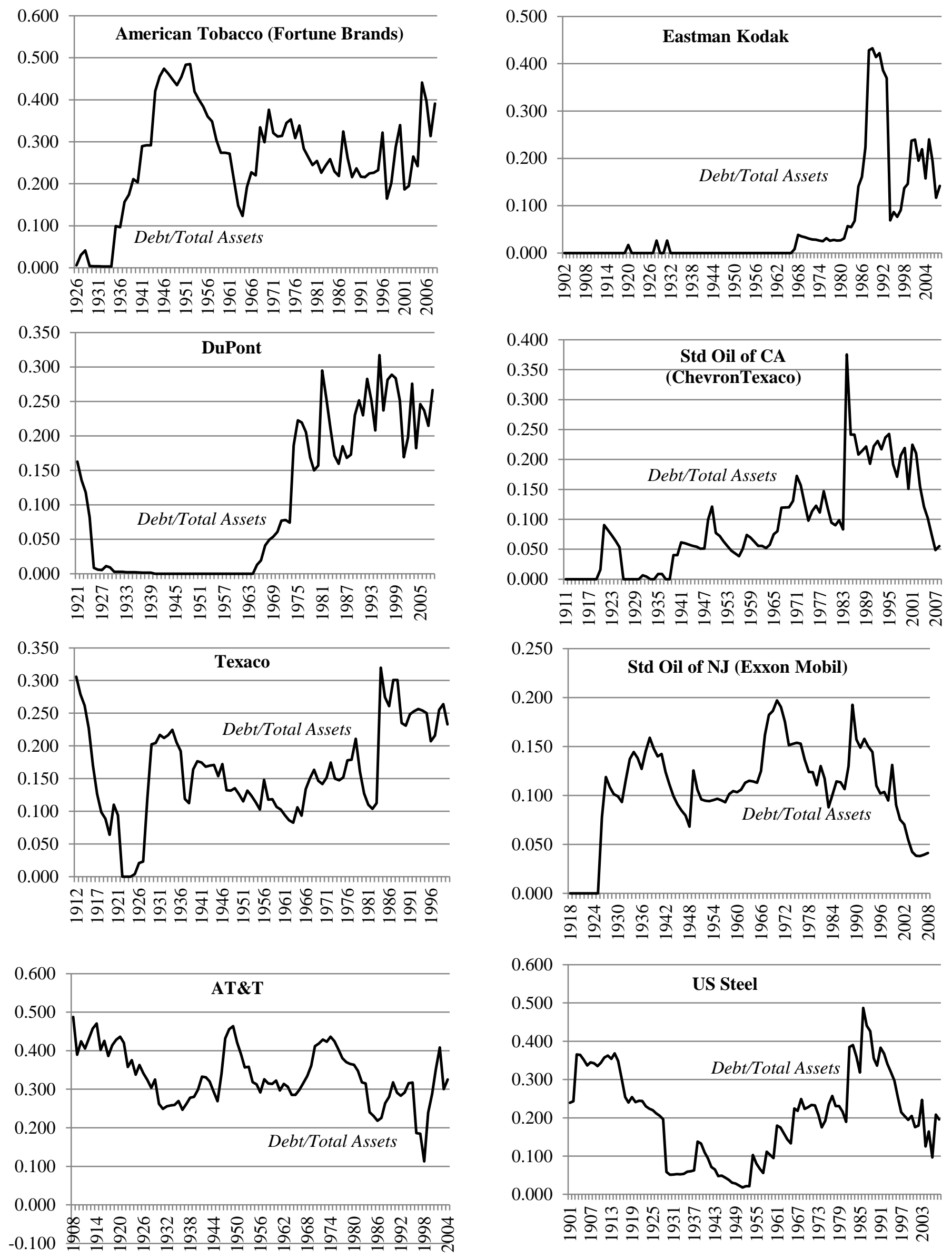

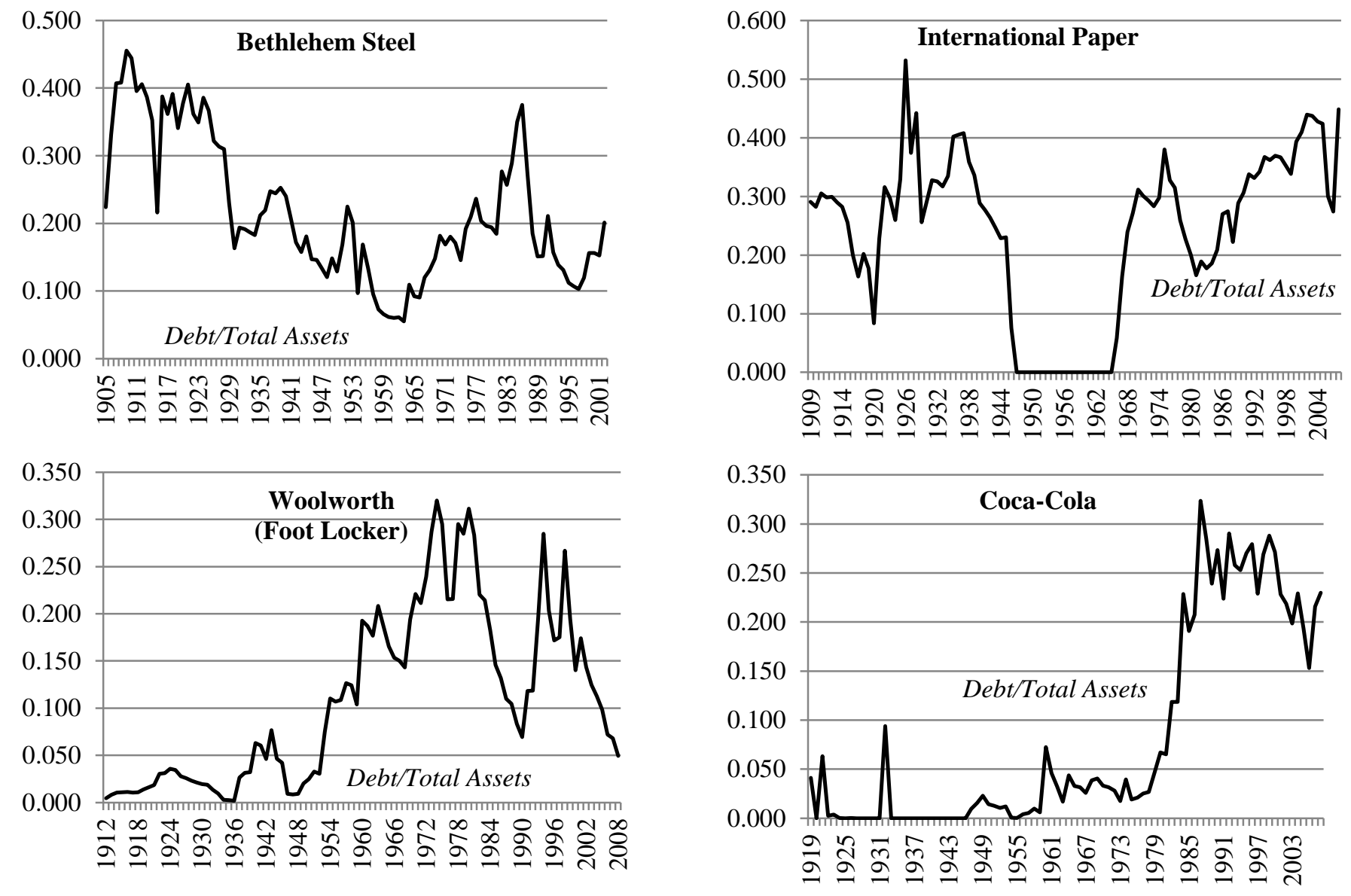


\section{Appendix B. Simulation Methods}

\section{Model definitions and parameters}

\begin{tabular}{|lc|}
\hline Simulated leverage for a given firm in year $t, L_{t}$, is governed by a & $L_{t}=\frac{e^{x_{t}}}{1+e^{x_{t}}}$ \\
logit transformation of an underlying state variable, $X_{t}$ & $X_{t}=\lambda \bar{X}+(1-\lambda)\left(X_{t-1}+\sigma \epsilon_{t}\right)$ \\
Underlying state-variable process, all parameters firm specific & $\lambda$ where $0.0 \leq \lambda \leq 1.0$ \\
Speed of adjustment (SOA) to target leverage ratio & $\bar{X}$ (varies across firms) \\
Target value stated in terms of the underlying state variable & $\epsilon_{t}$ \\
Random perturbation from a unit normal distribution & $\sigma$ \\
Volatility of time-series shocks to leverage & $\bar{X}_{t}=\delta X^{*}+(1-\delta)\left(\bar{X}_{t-1}+c ̧ \varepsilon_{t}\right)$ \\
\hline Target-generating process $(\delta=1$ for stationary target models) & $\mathrm{X}^{*}($ differs across firms) \\
Mean of a given firm's target leverage probability distribution & $\delta$ where $0.0 \leq \delta \leq 1.0$ \\
Speed at which target leverage reverts to X* & $\varepsilon_{t}$ (independent of $\left.\epsilon_{t}\right)$ \\
Random perturbation from a unit normal distribution & $c ̧$ \\
Volatility of target process & $\lambda=0.0$ everywhere \\
\hline Neutral-mutation model & $\lambda=0.0$ in zone; $\lambda>0.0$ outside \\
Target-zone models & $0.0<\lambda \leq 0.2$ outside zone \\
Flexible target-zone models & $\lambda \geq 0.5$ outside zone \\
Inflexible target-zone models & $\lambda=0.0$ over range of 0.300 \\
Wide zones & $\lambda=0.0$ over range of 0.100 \\
Narrow zones &
\end{tabular}

\section{Simulation algorithm}

For stationary target models, we analyze ten sets of target leverage ratios, with equal numbers of firms per target set. For example, one set posits 200 hypothetical firms with a target ratio of 0.1 , another 200 firms with a target of 0.2 , and so on up to 0.5 , with targets specified in L-terms. The other nine target sets: 0.1 , $0.2,0.3$, and $0.4 ; 0.1,0.2$, and $0.3 ; 0.1$ and $0.2 ; 0.1 ; 0.2$ to $0.6 ; 0.2$ to $0.5 ; 0.2$ to $0.4 ; 0.2$ and $0.3 ; 0.2$. The target-zone and neutral-mutation models work with these target sets, but posit $\lambda$ values as noted above.

For time-varying target models, we analyze the same ten target sets, except now the parameters refer to the means of the leverage target's probability distribution. For each target type in each simulation, we include 200 firms, i.e., 200 independent sample replications. Randomly chosen firms exit each simulation run over time at rates that match the years-listed distribution of the actual sample.

For each of the ten target sets, we create a grid of parameter-value combinations that apply to all firms and we treat each point in the grid as a "candidate" combination for the model under analysis. The grid consists of all combinations of (i) $\lambda$ ranging from 0.0 to 0.9 in increments of 0.1 , (ii) $\sigma$ ranging from 0.2 to 2.0 in increments of 0.2 , (iii) $\delta$ ranging from 0.0 to 0.9 in increments of 0.1 , and (iv) ç ranging from 0.1 to 1.0 in increments of 0.1 . For stationary target models, $\delta=1.0$ and so (iii) and (iv) are inoperative.

For each candidate model, we draw a sequence of shock realizations, which yield a time series of leverage observations for each firm and a sequence of leverage cross sections. For each firm in each simulation run, we start with ten shock realizations, and designate the resultant value as leverage at date $t=0$. We then draw 40 more shocks to leverage (and to target ratios in the time-varying targets analysis) and record leverage for each firm at dates $t=1,2, \ldots, 40$. After taking sample attrition into account (as noted above), we have a panel of model-generated leverage ratios, which we use to calculate $R^{2}$ s for sequential pairs of cross sections, just as Figure 3 reports for the real data. We conduct 50 simulation runs for each candidate model and work with the average $R^{2}$ s from those runs. 


\section{REFERENCES}

Chang, Xin and Sudipto Dasgupta, 2009, Target behavior and financing: How conclusive is the evidence? Journal of Finance 64, 1767-1796.

DeAngelo, Harry, DeAngelo, Linda, and Toni Whited, 2011, Capital structure dynamics and transitory debt, Journal of Financial Economics 99, 235-261.

Denis, David and Stephen McKeon, 2012, Debt financing and financial flexibility: Evidence from proactive leverage increases, Review of Financial Studies 25, 1897-1929.

Fama, Eugene and Kenneth French, 2002, Testing tradeoff and pecking order predictions about dividends and debt, Review of Financial Studies 15, 1-33.

Fama, Eugene and Kenneth French, 2005, Financing decisions: Who issues stock? Journal of Financial Economics 76, 549-582.

Fama, Eugene and Kenneth French, 2012, Capital structure choices, Critical Finance Review 1, 59-101.

Fischer, Edwin, Heinkel, Robert, and Josef Zechner, 1989, Dynamic capital structure choice: Theory and tests, Journal of Finance 44, 19-40.

Flannery, Mark and Kasturi Rangan, 2006, Partial adjustment toward target capital structures, Journal of Financial Economics 79, 469-506.

Frank, Murray and Vidhan Goyal, 2003, Testing the pecking order theory of capital structure, Journal of Financial Economics 67, 217-248.

Frank, Murray and Vidhan Goyal, 2008, Trade-off and pecking order theories of debt, in Espen Eckbo, ed.: Handbook of Empirical Corporate Finance (Elsevier B.V.).

Frank, Murray and Vidhan Goyal, Frank, 2009, Capital structure decisions: Which factors are reliably important? Financial Management 38, 1-37.

Frank, Murray and Tao Shen, 2013, Common factors in corporate capital structures, Unpublished manuscript, University of Minnesota.

Graham, John and Campbell Harvey, 2001, The theory and practice of corporate finance: Evidence from the field, Journal of Financial Economics 60, 187-243.

Graham, John and Mark Leary, 2011, A review of empirical capital structure research and directions for the future, Annual Review of Financial Economics 3, 309-345.

Graham, John, Leary, Mark, and Michael Roberts, 2013, A century of capital structure: The leveraging of corporate America. Unpublished manuscript, Duke University.

Harford, Jarrad, Klasa, Sandy, and Nathan Walcott, 2008, Do firms have leverage targets? Evidence from acquisitions, Journal of Financial Economics 93, 1-14.

Hennessy, Christopher and Toni Whited, 2005, Debt dynamics, Journal of Finance 55, 1129-1165. 
Hovakimian, Armen and Guangzhong Li, 2011, In search of conclusive evidence: How to test for adjustment to target capital structure, Journal of Corporate Finance 17, 33-44.

Huang, Rongbing and Jay Ritter, 2009, Testing theories of capital structure and estimating the speed of adjustment, Journal of Financial and Quantitative Analysis 44, 237-271.

Kisgen, Darren, 2006, Credit ratings and capital structure, Journal of Finance 61, 1035-1072.

Kisgen, Darren, 2009, Do firms target credit ratings or leverage levels? Journal of Financial and Quantitative Analysis 44, 1323-1344.

Korteweg. Arthur, 2010, The net benefits to leverage, Journal of Finance 65, 2137-2170.

Korteweg, Arthur and Ilya Strebulaev, 2013, An empirical (S,s) model of dynamic capital structure, Unpublished manuscript, Stanford University.

Lambrecht, Bart and Stewart Myers, 2012, A Lintner model of payout and managerial rents, Journal of Finance 67, 1761-1810.

Leary, Mark and Michael Roberts, 2005, Do firms rebalance their capital structures? Journal of Finance 60, 2575-2619.

Lemmon, Michael, Roberts, Michael, and Jaime Zender, 2008, Back to the beginning: Persistence and the cross-section of corporate capital structure, Journal of Finance 63, 1575-1608.

Mackay, Peter and Gordon Phillips, 2005, How does industry affect firm financial structure? Review of Financial Studies 18, 1433-1436.

Mayer, Colin and Oren Sussman, 2004, A new test of capital structure, Unpublished manuscript, University of Oxford.

Miller, Merton, 1977, Debt and taxes, Journal of Finance 32, 261-276.

Minton, Bernadette and Karen Wruck, 2001. Financial conservatism: Evidence on capital structure from low leverage firms, Unpublished manuscript, The Ohio State University.

Modigliani, Franco and Merton Miller, 1958, The cost of capital, corporation finance, and the theory of investment, American Economic Review 48, 261-197.

Myers, Stewart and Nicholas Majluf, 1984, Corporate financing and investment decisions when firms have information that investors do not have, Journal of Financial Economics 13, 187-221.

Parsons, Christopher and Sheridan Titman, 2008, Empirical capital structure: A review, Foundations and Trends in Finance, 1-93.

Rajan, Raghuram and Luigi Zingales, 1995, What do we know about capital structure? Some evidence from international data, Journal of Finance 50, 1421-1460.

Rauh, Joshua and Amir Sufi, 2011, Explaining corporate capital structure: Product markets, leases, and asset similarity, Review of Finance 16, 115-155.

Scheffé, Henry, 1959, The Analysis of Variance (John Wiley \& Sons, New York, NY). 
Strebulaev, Ilya and Baozhong Yang, 2013, The mystery of zero-leverage firms, Journal of Financial Economics 109, 1-23.

Taggart, Robert, 1985, Secular patterns in the financing of U.S. Corporations, in Benjamin Friedman, ed.: Corporate Capital Structures in the United States (University of Chicago Press).

Uysal, Vahap, 2011, Deviation from target capital structure and acquisition choice, Journal of Financial Economics 102, 602-620.

Van Binsbergen, Jules, Graham, John, and JIE Yang, 2010, The cost of debt, Journal of Finance 55, 2089-2136.

Welch, Ivo, 2004, Capital structure and stock returns, Journal of Political Economy 112, 106-131. 